\title{
Leibniz on the Continuity of Space
}

\author{
VINCENZO DE RISI
}

Abstract: The present essay describes Leibniz's foundational studies on continuity in geometry. In particular, the paper addresses the long-debated problem of grounding a theory of intersections in elementary geometry. In the early modern age, in fact, several mathematicians had claimed that Euclid's Elements needed to be complemented with additional axioms in order to ground the existence of the intersection points between straight lines and circles. Leibniz was sensible to similar foundational issues in the Euclidean tradition, and dedicated several studies to investigate a good definition of the continuity of space, in order to ground a general theory of intersections of curves and surfaces. While Leibniz's researches on continuity in relation with the Calculus have been extensively studied in the past, the present essay deals with the less-known Leibnizian notion of a continuous space, as it is to be found in several unpublished writings preserved in Hannover. The subject widens as to encompass the relation between mereology and analysis situs, Leibniz's studies on a geometrical characteristics, and Leibniz's theory of space at large.

Acknowledgements. I thank the Max Planck Institute for Mathematics in the Sciences and his director Jürgen Jost for providing me with the possibility of writing a good part of this paper while I was based in Leipzig, and more in general for having fostered important occasions of discussion with other Leibniz scholars. I also thank Richard Arthur, Eberhard Knobloch, Julien Narboux and Erich Reck, who have discussed with me this paper in several occasions; and Andrea Costa, Siegmund Probst and Javier Echeverría for sharing with me some unpublished papers by Leibniz.

\section{\$1. Introduction.}

The notion of continuity spreads throughout Leibniz's thought to such an extent that it may be impossible to find a single topic of debate, among the hundreds that the great man tackled in his life, in which he did not use it to foster his ideas or defend his positions. Continuity represented for him a formidable heuristic tool in mathematics and in logic, in physics and the sciences of life, in metaphysics and epistemology, and on this notion he was able to build some of his most daring intellectual constructions, as well as several important arguments that he employed in defending his views. Given the breadth of the use of continuity in Leibniz's works, it does not come as a surprise that it may be difficult to pinpoint a common meaning underlying all the applications of the word, and in fact it is 
easy to conclude, when browsing Leibniz's papers, that he was working rather with a family of connected and yet different (and sometimes pretty vague) notions of continuity which do not admit of reduction to any precise and common core.

If, however, we restrict our investigations to the mathematical meaning of continuity, we may be able to mark out a certain number of exact definitions of this concept that Leibniz was able to fashion and formalize in the hope, and indeed in the need, to ground his new analytical discoveries. Such mathematical definitions of continuity may be broadly arranged into two groups, dealing respectively with the concepts of function and of space. Leibniz was able to provide a very good definition of a continuous function (even though he never arrived at any formal definition of a function itself) or of continuous transformation, which may be easily compared with Weierstrass's celebrated definition of this latter, through the $\varepsilon-\delta$ formalism, which is still in use today. ${ }^{1}$ Such definition was perfectly natural within the context of the new infinitesimal Calculus that Leibniz was inventing and developing and was largely unprecedented in the mathematical literature, which had had no need, in previous centuries, of dealing with this kind of transformations in such an exact way.

On the other hand, Leibniz also needed a completely different concept of continuity: one that might apply not to transformations or functions but rather to space and figures. He needed, in short, a good definition of what it means to say that a line, a surface, or space itself are (or may be) continuous objects. This notion of the continuity of things (rather than functions), far from being invented only in the $17^{\text {th }}$ Century, had been a topic of discussion since antiquity and had long since represented a lively source of debate and controversy. In the course of the centuries many different meanings had accumulated and accreted around this notion, which remained, on into modernity, more the object of a vague, intuitive understanding than of any exact formulation. As a matter of fact, when it was fully formalized in the $19^{\text {th }}$ and $20^{\text {th }}$ Centuries, this notion of continuity simply exploded in a huge array of different meanings, each of them capturing a few features of the intuitive (historical) understanding of a continuous whole. The effect of this formal analysis of the concept of continuity was that the expression "continuous space" (or surface, line, etc.), which had been so common at the time of Leibniz and during many centuries, disappeared altogether and has, today, no meaning at all in contemporary geometry. We rather speak, for instance, of metrically complete spaces, or connected spaces, arcwiseconnected spaces, geodesically-connected spaces, locally compact spaces, dense spaces, separable spaces, regular or semi-regular spaces, normal spaces, and so forth. Some of these notions are connected to one another through complex relations and difficult topological theorems, and it proved impossible to preserve any unitary concept of spatial continuity. The space and figures employed in classical geometry (from antiquity up to the early modern age) are "continuous", indeed, in several of the above-mentioned senses. The notion of "connectedness", for instance, the naïvely-grasped meaning of which is just that a figure comes in one piece, was certainly easy to conceive of, and thematize, as an aspect of continuity; but it is also a notion insufficient to justify many unspoken geometrical assumptions of classical mathematics. The notion of "completeness" is considerably less

\footnotetext{
${ }^{1}$ These very famous Leibnizian definitions may be found in his Lettre sur un principe général, published in 1687 (GP III, pp. 51-55); and the related essay Principium quoddam generale (A VI, 4C, n. 371, pp. 20312039; GM VI, pp. 129-35).
} 
intuitive and considerably more difficult to formalize; it is also much more important; yet it fails to capture the intuitive notion of continuity, as a discrete set may well be a complete one (e.g. $\mathbb{Z}$, the set of integer numbers). "Density" is another notion that had been easily intuitively grasped ever since antiquity (at least in its less formal meaning of infinite divisibility); and, while it is not strong enough to justify many continuity assumptions in Euclidean geometry, a figure (or space) which is both dense and complete may well be a reasonable candidate for being "continuous" in the intuitive sense. The latter notion might perhaps also be expressed through "compactness", since a totally limited subspace within a metric space is complete if, and only if, it is compact (and figures were limited in Greek geometry); nonetheless, the notion of compactness is quite an abstract one, and proved especially difficult to define in general terms. The topological "separation" properties also play a role in this conceptual framework, as they may help, for instance, in formalizing the notion of "contiguity" as distinguished from continuity; but they are not immediately useful in defining the latter. Even the famous Axiom of Archimedes (which rules out the possibility of infinitesimal magnitudes) has several connections with the notion of continuity; once again, though, it cannot, taken alone, be considered to be a viable expression of this latter notion ( $\mathbb{Z}$ trivially fulfills such an axiom). In short, an entire galaxy of different notions is needed in order to formalize and axiomatize the "continuity" of space. It is not surprising, therefore, that, as long as early modern mathematicians were committed to expressing a single concept which would capture and draw all these meanings together, their efforts were doomed to failure.

Leibniz himself, then, who had, on the one hand, been able to produce a single definition of a continuous function and apply it throughout his works, was obliged, on the other hand, to experiment with several definitions of the continuity of space and spatial objects, each of which may be seen as an attempt to grasp one of the above-mentioned concepts. It is remarkable, however, that Leibniz's last and most fully articulated definition of the continuity of space has several points in common with the modern understanding of metrical completeness. The latter was first defined by Richard Dedekind in 1858 and presented in print in his celebrated work on Stetigkeit und Irrationale Zahlen (1872), in order to define the real number field (which is the smallest complete extension of the field of rational numbers). Such notion, and its variants due to Cantor and Weierstrass, still plays the most important role in the domain of the foundations of mathematics, and was accepted by Hilbert in his axiomatization of continuity in his Grudlagen der Geometrie (1899). ${ }^{2}$

It is true, indeed, that Dedekind stressed that his own definition of the real numbers was un-geometrical in the sense that it did not have recourse to any consideration of geometrical magnitudes (such as segments of incommensurable length). He also strongly protested whenever anyone compared his construction of the real field to those of others (such as Bertrand's) which grounded arithmetical properties on the continuity of segments. On the other hand, however, Dedekind's case was that the continuity of segments had not itself been established beforehand, and that therefore any geometrical construction of real

\footnotetext{
${ }^{2}$ See HilberT (1968, first ed.1899), \$8, pp. 30-33; the Axiom of Completeness was added in the French first edition (1900) and the second German edition (1903), and that on Linear Completeness (a variation of the previous one) in the seventh German edition (1930). On the history of Hilbert's completeness axiom, see GIOVANNINI (2013).
} 
numbers could not help but miss the target of a rigorous foundation. He even claimed that the only way he saw to define the continuity of geometrical magnitudes was to reshape those considerations on ordering that he had applied to numbers into analogous considerations on the disposition of the points of a segment. So that the only way to directly ground the continuity of geometry would have been to mimic Dedekind's own definition for number theory. ${ }^{3}$ Such a (very simple and yet extremely powerful) definition of geometrical continuity is formulated as follows:

If all points of the straight line fall into two classes such that every point of the first class lies to the left of every point of the second class, then there exists one and only one point which produces this division of all points into two classes, this severing of the straight line into two portions. ${ }^{4}$

Such an axiom is in fact sufficient to rigorously prove all propositions of elementary geometry — and much more. ${ }^{5}$ Dedekind's idea of the completeness of a straight line has a remarkable historical relevance for our study, as most of the attempts to define continuity in the early modern age were purely geometrical, and aimed at establishing the continuity of segments rather than the completeness of real numbers. Dedekind's idea that a formalization of continuity in geometry should be formulated in a similar way to the one employed in building the real field permits us to draw insightful comparisons between these modern endeavors and Leibniz's (and others') earlier attempts. We should note that Dedekind's geometrical formulation of his notion of completeness assumes that a line is actually composed by points (in some set-theoretical or topological sense of "composition"), and that this latter fact was one that was generally denied in antiquity and in the early modern era. We see, therefore, that any formulation of completeness attempted

\footnotetext{
${ }^{3}$ This is hinted in the first ed. Vorwort to Dedekind's Was sind und was sollen die Zahlen?, where Dedekind discusses Jules Tannery's construction of continuity and denies Tannery's claim that a similar definition of real numbers had been given by Bertrand-since Bertrand had employed geometrical considerations, and therefore had to appeal to the continuity of space. The continuity of space, however, was simply assumed by Bertrand (and others) as "intuitively" given - something which Dedekind argued to have been a serious mistake, since a dense space, for instance, would still be intuited in the same way. On the contrary, notwithstanding the fact that we may subjectively begin, when examining what continuity is, from a notion formed with the help of spatial intuition (as Dedekind himself did in his work), we may only claim to have an exact definition of the continuity of space when we have already moved to logical considerations and a proper definition of the continuity of numbers: "All the more beautiful it appears to me that without any notion of measurable quantities [i.e. spatial magnitudes] and simply by a finite system of simple thought-steps man can advance to the creation of the pure continuous number-domain; and only by this means, in my view, is it possible for him to render the notion of continuous space clear and definite" (DEDEKIND 1932, vol. 3, p. 340; Engl. transl. Beman). Dedekind's explicit reference was to his previous work on Stetigkeit und irrationale Zahlen, and in particular to its $\$ 3$, in which he had given (see the next footnote) a geometrical reformulation of his definition of the completeness of real numbers through Dedekind's cuts.
}

\footnotetext{
${ }^{4}$ The passage comes from $\$ 3$ of Stetigkeit und irrationale Zablen, and the original runs: "Zerfallen alle Punkte der Geraden in zwei Klassen von der Art, daß jeder Punkt der ersten Klasse links von jedem Punkte der zweiten Klasse liegt, so existiert ein und nur ein Punkt, welcher diese Einteilung aller Punkte in zwei Klassen, diese Zerschneidung der Geraden in zwei Stücke hervorbringt" (DEDEKIND 1932, vol. 3, p. 322; Engl. transl. Beman).

${ }^{5}$ An explicit proof that Dedekind's completeness allows one to prove the existence of the intersection points needed in elementary geometry is in HEATH (1925), vol. 1, pp. 237-40; see also VITALI (1923, pp. 210-12).
} 
before the $19^{\text {th }}$ Century had necessarily to find a different way of approaching such a definition.

It should be noted, in fact, that, while Leibniz was naturally led to define the continuity of a function by his studies on infinitesimal analysis, his researches on the definition of the continuity of space were only partially elicited by these new discoveries and were rather discussed in Leibniz's logical and epistemological writings on the foundations of geometry. These papers, which Leibniz often denominated, quite generally, as his new enterprise of an analysis of situation (analysis situs), dealt with many foundational issues in geometry, extending from the proof of Euclid's axioms to the definitions of the basic relations of similarity and congruence, from a discussion on tridimensionality to new demonstrations of ancient theorems - and on, indeed, to many other topics besides. ${ }^{6}$ Most of these Leibnizian writings referred to Euclid's Elements, which was the text that had always to be commented upon when dealing with the foundations of mathematics. The issue of the continuity of space, therefore, found its natural place in this kind of investigation. It is important to understand, in any case, that Leibniz's foundational studies on continuity were quite new, and that, even if the tradition of commentaries on Euclid could already boast a history of two millennia, the issue of continuity had only seldom been referred to therein, so that, in the $17^{\text {th }}$ Century, this issue was looked upon as a remarkably new problem in the foundational domain.

The locus classicus for the debate, at the time, was Euclid's demonstration of Elements I, 1.

\section{\$2. Euclid's gaps and Aristotle’'s continuity.}

The first proposition of Euclid's Elements teaches how to draw an equilateral triangle on a segment assumed as its side. The problem is solved by tracing two equal circles having as their centers the ends of the given segment and as their radius the length of the segment itself. The two circles intersect at a point above the segment, and the triangle is drawn by connecting, with straight lines, the newly-found point with the two ends of the given segment. The possibility of the

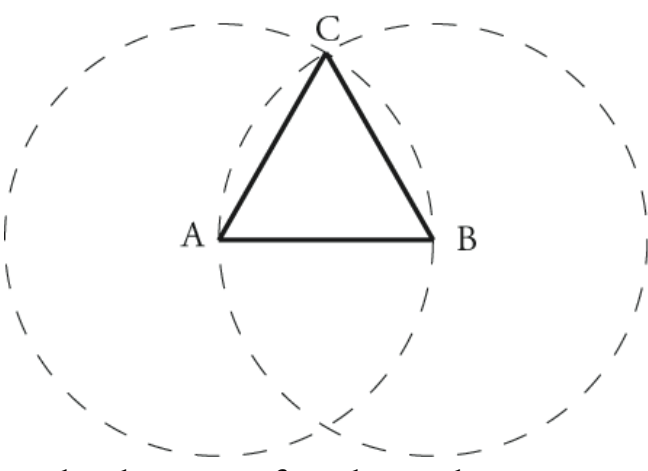
construction is grounded in Euclid's Postulate 3, that allows the drawing of circles with any center and radius, and on Postulate 1, that allow the connection, by straight lines, of any pair of points. The equality of all three sides of the triangle is grounded, in turn, in the definition of a circle, all the radii of which are equal to one another (thus $A B=A C$ and $A B=B C$ ), and in Euclid's Common Notion 1, which states that things equal to the same thing are also equal to one another (thus $A C=B C$ ).

\footnotetext{
${ }^{6}$ For a treatment of Leibniz's investigations on analysis situs and geometry in general, see my DE RISI (2007, and 2015). The main Leibnizian essays on analysis situs are still to be found in the fifth volume of the $19^{\text {th }}$ Century edition of Leibniz's mathematical writings, edited by Gerhardt (GM VII, pp. 141-211). A useful collection of Leibniz's early essays on the same topic (in the original Latin and French translation) may be found in J. ECHEVERría, M. PARMENTIER (1995).
} 
Despite the number of principles employed by Euclid to ground his first and simplest proof, modern interpreters object that one extremely important passage was overlooked, namely the assumption of the existence of the point of intersection $C$ of the two circles. This requirement, the existence of the point of intersection, is read, in turn, as a requirement of continuity: the plane underlying Euclid's constructions should be sufficiently continuous to guarantee the existence of every point of intersection between circles, and of this one in particular. Euclid, however, provided no justification, either in his system of principles (postulates and common notions), or in any of his proofs, for the existence of the intersection points. In particular, the notion of continuity was never thematized in any ancient mathematical text, and neither Euclid, Archimedes, nor Apollonius ever mentioned this notion in their works (or defined geometrical objects as "continuous"). If they had any sort of implicit theory about intersections, it was surely based on other grounds than a notion of continuity. ${ }^{7}$

This notwithstanding, the notion of continuity ( $\sigma \cup v^{\varepsilon} \chi \varepsilon\llcorner\alpha)$ was explicitly thematized in a few philosophical discussions during antiquity, and Aristotle played here the most prominent role. Even though Euclid and the other Greek mathematicians were probably unaware of (or uninterested in) Aristotle's contribution on the subject, the importance of his conception grew with the passing of the centuries, and already at the time of the Roman Empire several commentators on ancient mathematical texts were blending the thought of Euclid with certain Aristotelian elements. In this connection, continuity made its appearance in a few mathematical texts or paratexts of late antiquity, which were in turn transmitted to the Middle Ages and the Renaissance. In the early modern age, when a fuller discussion on space and continuity in geometry was gaining ground, the influence of Aristotle and his definition of this notion became paramount: so that it is impossible to ignore Aristotle's contribution to the topic even if it was not originally intended to implement the foundations of mathematics. Leibniz himself, in his attempt to build a new mathematical definition of the continuum could not help but begin by reinterpreting the old Aristotelian definition.

The first definition, or perhaps a characterization, of continuity that can be found among Aristotle's works states that a continuous quantity (a magnitude) is such that all its parts are themselves magnitudes, and are thus composed of further parts that are also magnitudes (and so on). This directly entails the infinite divisibility of a continuous quantity, and seems to amount (in modern terms) to equating continuity with density. ${ }^{8}$ Aristotle's aim in proposing such a definition seems to have been that of critiquing several forms of atomism extant at the time in natural philosophy. In these passages, he always treats continuity as a monadic property. ${ }^{9}$

\footnotetext{
${ }^{7}$ As a matter of fact, I do think that Euclid and other Greek mathematicians may have had a solution to the problem of intersections, that was grounded on a subtle combination of diagrammatic inferences and the definition of a point. I have presented some evidence for this claim in my DE RISI (forthcoming A)

${ }^{8}$ We might also make a distinction between infinite divisibility and density, as the latter mathematical property seems to imply that a magnitude is composed by points-which is not the Aristotelian assumption. I will nonetheless conflate the two expressions from time to time, as they seem to be equivalent under many foundational respects, and the modern notion of density helps to shed light on the actual strength of certain axioms and assumptions. I thank Richard Arthur and Viktor Blasjo for stressing this point with me.

${ }^{9}$ This meaning of continuity as density is to be found in De cael. A 1, 268a7-8, where it seems to be presented as a definition. The idea that a continuous whole cannot be resolved into elements that have no
} 
Aristotle's argument for infinite divisibility also aimed to prove that a continuous whole cannot be composed of points. This latter consequence of Aristotle's definition of continuity is very important and marks a milestone in the history of thought. It represented the main counter-thesis advanced by innumerable generations of philosophers and mathematicians against the Zenonian theses on the composition of the continuum. Aristotle, by rejecting the possibility of composing a magnitude from indivisibles, became committed to accepting extended quantities as the basic elements of geometry and thus to regarding points (or lines with respect to surfaces, and surfaces with respect to bodies) as mere boundaries of more primitive continuous wholes. In this respect, the modern settheoretical approach to geometry, which starts from a set of points and constitutes a "continuous" manifold (whatever "continuity" may mean in its different contexts) by means of a further set of topological (or ordering) relations among points, is completely extraneous to the foundational perspective of antiquity. Aristotle's understanding of a magnitude is in fact more closely related to those "post-modern" mathematical theories, such as pointless geometry, region-based topology, or the theory of locales, which (not unaware of the Aristotelian position on this issue) have developed tools to deal with continuity which are alternative to the set-theoretical approach. ${ }^{10}$ All ancient geometers seem to share this point of view (even if they may have not shared, or even known of, Aristotle's arguments for it), and their mathematical constructions are grounded in a multisorted ontology, in which points, lines, surfaces, and solid bodies remain distinct from, and irreducible to, one another. ${ }^{11}$ This has important consequences for the mathematical theory of intersections.

The Aristotelian notion of density is liable to a purely mathematical treatment. It comes as no surprise that already in late antiquity a few mathematicians were to define continuity, in geometrical treatises, as density (of course, there is no reason to think that they had in mind Aristotle's discussion in particular). Density, however, is not suitable to ground the Euclidean theory of intersections, since this latter requires some stronger

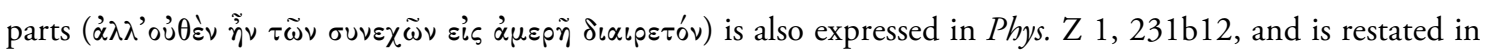
Phys. Z 2, 232a23-25. In both passages of the Physics, the definition appears as a characterization of the definition given by the notion of a common boundary. The simpler idea that a continuous whole is

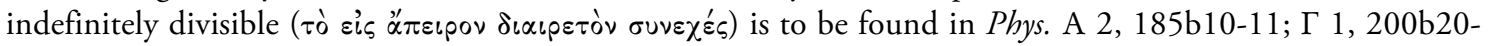
21; and Z 8, 239a23. A magnitude (which is a continuous quantity) is said to be indefinitely divisible in Phys. Z 6, 237a33-34.

${ }^{10}$ Among the numerous mathematical studies in these fields, I will mention here ROEPER (2006), which gives a theory of continuity without quantifying on points, but rather on extended regions. Roeper's system manages to recover Dedekind completeness, in this different setting, through a strong axiom on the completeness of a Boolean algebra employed in the formalization. A different axiomatization of linear regions which also entails completeness is given in the important HELlmAN, SHAPIRO (2013), which is more historically sensitive than Roeper's paper. The authors have further developed their views in LINNEBO, SHAPIRO, HELlman (2015), which limits the use of the actual infinite in order to better comply with Aristotelian conceptions of mathematics (but, in doing so, it loses completeness). The paper HELLMANN, SHAPIRO (2015), further shows how to extend to two dimensions the previous results for linear regions. The latter three articles have been recently collected in the volume HELLMAN, SHAPIRO (2018). For a survey of the most important modern contributions on pointless continuity (which date at least from Whitehead's seminal studies from the 1910s), see CALOSI, GRAZIANI (2014).

${ }^{11}$ I will not discuss here Archimedes' Method and his theory of indivisibles, which presents several interpretive difficulties. In any case, it seems not to have had any impact on the theory of intersections itself. 
continuity principle. In modern terms, a plane that should only contain points with rational coordinates would be dense (i.e. its parts would be infinitely divisible), but the intersection of the two circles in Elements I, 1 could still be missing.

In the Aristotelian corpus, however, we also find a more fundamental definition of continuity. The latter states that two things are continuous with one another if they touch one another and their boundaries are one and the same. ${ }^{12}$ The subtlety of the definition mainly consists in its difference from the Aristotelian notion of contiguity: two bodies are said to be contiguous if they touch, but their boundaries are not one and the same. The definition of "touching", or being in contact, seems to be given by the overlapping of the boundaries of a thing (i.e. these are together, $\alpha^{\prime} \mu \alpha$, and therefore occupy the same place, $\tau o ́ \pi \circ \varsigma)$. This definition would allow two contiguous things to be in contact while still allowing them to move one with regard to the other. This is the case inasmuch as their boundaries are not, here, unified in a stronger sense and may, therefore, "slide" one upon the other. So, for instance, a wheel is contiguous to (but not at the same time continuous with) the path in which it revolves, and the water is contiguous to the body submerged in it. A wooden table, on the other hand, is continuous inasmuch as two parts of it are not only in contact with one another but are held together by one common boundary.

It should be clear that such a definition was originally conceived as a relation between physical objects and was employed by Aristotle to explain his conception of motion. ${ }^{13}$ Its use was later extended by commentators to encompass other domains, such as the continuity of colors and sounds or the continuity of geometrical objects; but its original aims seem not to have been so general. Outside of the physical domain, in which the motion of bodies immediately reveals the divide between contact and continuity (or concurrent motion), it is hard to get a firm and precise grasp on Aristotle's distinction between contiguity and continuity. That is to say, it is hard to say exactly what it means for two boundaries to be not only in the same place but also unified in some further way, and a large amount of exegetical discussion has been spent, during the centuries, in attempting to better spell out this latter distinction. While several metaphysical solutions to the problem might perhaps be found, a purely mathematical treatment of the difference between two coinciding points and one single point is not easy to envisage (using the tools of classical geometry alone). ${ }^{14}$ It should also be noted that Aristotle generally excluded the possibility that two extensions $(\delta\llcorner\alpha \sigma \tau \eta \dot{\eta} \mu \tau \alpha)$ could share the same place or be together in any sense.

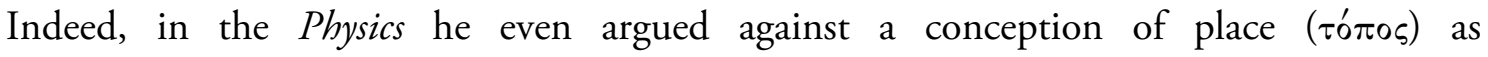

\footnotetext{
12 The Aristotelian definition of continuity by the notion of a common boundary is especially expounded on in Phys. E 3, 227a10-13.

${ }^{13}$ The distinction between contiguity and continuity in relation to motion is especially worked out in Phys. $\Delta$ 4, 211a24-b4, where Aristotle says that if a body is contained in another body and continuous to it, the former body is a part of the latter; while if it is contained and contiguous to it, the latter body is the place of the former. In the first case, the bodies move together; in the second case, the first body moves in the second as in its place. The Aristotelian idea that two bodies are continuous with one another when they move together (see also Metaph. $\Delta 6,1016 \mathrm{a} 5-6$; I 1, 1052a20) had an important posterity in the modern era and in Leibniz in particular.

${ }^{14}$ Ibn Rushd, for instance, will later claim that the Aristotelian distinction between contiguity and continuity is only viable in physics, whereas in mathematics two figures are either continuous or completely apart from one another (i.e. their boundaries are either together and one, or not together at all). See some references in SYLLA (1982).
} 
tridimensional extension on the grounds that, if place were so defined, then it and the located body would be two extensions overlapping together. ${ }^{15}$ This directly entails that Aristotelian magnitudes cannot have a common part. It is not entirely clear how this general impossibility of overlapping can possibly be dropped in the case of boundaries. It is clear, however, that boundaries of parts should be allowed to overlap and be common to different magnitudes. ${ }^{16}$ Moreover, Aristotle elsewhere argued that boundaries cannot "be in a place" in any proper sense. Much less, then, can they share a common place. These (and other) conceptual difficulties brought several Aristotelian commentators to modify, or utterly reject, Aristotle's definition.

A further important feature of Aristotle's definition of continuity should also be highlighted: rather than defining a continuous whole, Aristotle always considers the continuous connection of the parts forming it. In other words, continuity is not a property of a thing but rather a relation between two (or more) things which are disposed (or situated) in a certain way with respect to one another (i.e. with touching and identified boundaries). The latter aspect of the notion implies that continuity cannot be attributed, as such, to certain magnitudes and figures, but only to the points where they join with one another. It is true, however, that Aristotle himself spoke quite often of "continuous wholes", employing the term as a monadic predicate; even more often he talked about the

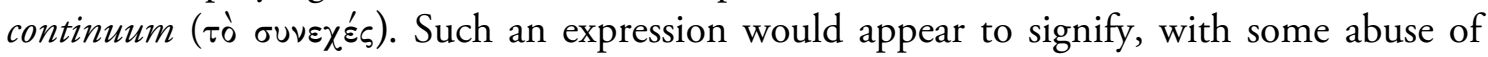
language, that the parts of such a whole are continuous with one another (in the relational sense). Aristotle normally has in mind actual parts, that is to say a whole which is divided into (continuous) parts by means of some internal criterion. A broken line, for instance, forming an angle, may be said to be "continuous" insofar as the two segments constituting it are continuous with one another in the common vertex. Thanks to this kind of continuity, the broken line constitutes a unity of some sort, notwithstanding the fact that its unity, according to Aristotle, is not a unity per se ( $\left.x \alpha \theta^{\prime} \alpha u \tau^{\prime} o ́ v\right)$. A straight, unbroken line, on the other hand, does indeed possess a unity in itself, but could hardly be conceived of as continuous in the Aristotelian sense. This is so because it is not made up of actual parts and therefore no continuity in the relational sense may be attributed to it. ${ }^{17}$

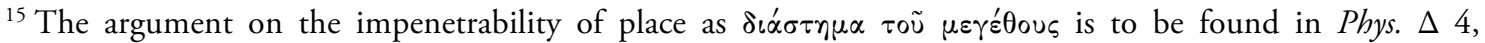
211b19-25. Aristotle also simply states the idea that two mathematical bodies cannot interpenetrate, and therefore cannot have parts in common, in Metaph. B 2, 998a12-15; M 2, 1076b1-2.

${ }^{16}$ A less metaphysical and more mathematical explanation of the impossibility of the overlapping of parts may be derivable from the fact that quantity is for Aristotle just a set of parts, in the sense that measuring it amounts to counting its parts. This would be ill-defined, of course, if one were to admit the possibility of overlapping parts. Boundaries, however, have, in any case, "zero measure" and therefore they may freely overlap.

${ }^{17}$ The passages on the broken line in Aristotle are to be found in Metaph. $\Delta$ 6, 1016a2-3, and 12-13. Bonitz

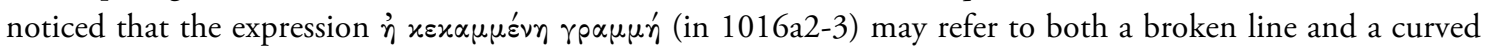
line (as in ARIST. De inc. anim. 9, 708b22), but the following passage (1016a12-13) clarifies that Aristotle had in mind the former (cf. BONITZ 1848, p. 235). This passage has been a source of puzzlement for many commentators, especially since in Phys. $\Theta$ 8, Aristotle states that a motion in a broken trajectory should be considered to be discontinuous. Yet in the latter passage he seems to have in mind that a moving object, in order to make a turn at an angle, would have to stop; and coming to a stop is "the contrary of motion" and would therefore imply a discontinuity in motion. The problem, therefore, would be the continuity of motion but not the continuity of the line traced by the motion. In fact, a motion along a broken line is said to be continuous in Phys. E 4, 229a2. I thank Marco Panza for a discussion on this point that helped me to clarify
} 
It is also true that, in some other passages, Aristotle seems to hold that it is possible to consider something to be continuous (intended here as a monadic predicate) even if its continuously connected parts are only potential. In this sense a table may be said to be continuous inasmuch as the potential parts of it are all continuous with one another. It should be clear, however, that the potential parts of a table are still thought of in physical, rather than mathematical, terms: Aristotle is thinking of a few determinate parts of the whole that have not yet been spelled out (and sometimes he talks about nails or glue to enforce continuity). Nowhere does he make any allusion to the idea that, in order to ascribe continuity to a whole, one should have to consider all possible parts of it, in abstract and mathematical terms, as well as their reciprocal continuity relations. ${ }^{18}$ In this respect, Aristotle at no point suggests a structural definition of continuity (i.e. one in which continuity would be a monadic property stemming from the system of relations among all possible parts of a whole), and generally intends this notion rather as a simple relational property.

Compared with the characterization of continuity as infinite divisibility, Aristotle's "physical" definition of continuity has a less mathematical outlook. Nonetheless, a few modern interpreters adopt the optimistic stance of recognizing in the Aristotelian definition a topological (or "proto-topological", as they put it) notion of connectedness. ${ }^{19}$ While the intuitive idea of topological connectedness is clearly hinted at by Aristotle's definition, I think it is a bit of a stretch to see an exact characterization of such a property in this latter. The notion of connectedness relies, in an essential way, on a distinction between closed and open sets and, while Aristotle certainly has and employs a notion of a boundary, this seems insufficient to clearly establish the distinction at stake here. Most of all, however, Aristotle's failure to consider all possible parts of a whole (i.e. his lack of a structural approach to the notion) seems to preclude our attributing to him the distinction of having been the first to formulate the mathematical concept of connectedness, which requires the possibility of quantifying on all possible subsets of a given set. ${ }^{20}$ In any case, whereas the relation between

my views. Panza has dealt with Aristotelian continuity in relation to the geometrical theory of intersections in PANZA (1992); and in a longer, forthcoming paper, an early draft of which he was so kind to share with me. Aristotelian and Euclidean continuity have been compared also by CAVEING (1982).

\footnotetext{
${ }^{18}$ The Aristotelian notion of a potential part should not be conflated with the modern notion of a possible part. The distinction seems to acquire some importance if we consider that parts, for Aristotle, are impenetrable (see above). A segment $\mathrm{AD}$, in which we specify two intermediate points $\mathrm{B}$ and $\mathrm{C}$, can be conceived of as constituted by two (continuous, potential) parts $\mathrm{AB}$ and $\mathrm{BD}$, and it can also be conceived of as constituted by two different (continuous, potential) parts $\mathrm{AC}$ and $\mathrm{CD}$. But it is impossible to conceive of these partitions together, for in this case parts $\mathrm{AB}$ and $\mathrm{AC}$ would overlap with one another. We may also recall that Aristotle endorsed a "statistical" notion of possibility, according to which something is possible if it is real at a given time. This notion is scarcely applicable to mathematics in any case.

${ }^{19}$ For the recent history of the notion of connectedness, see WILDER (1978).

${ }^{20}$ The main effort in this direction has been made by WHITE (1988). White offered some more pieces of evidence for his thesis in his later, and lengthier, work WHITE (1992), which deals, however, mostly with the physical notion of continuity. White's main point in establishing the modern notion of connectedness from Aristotle's definition is grounded in the statement that Aristotle never considered the existence of open intervals. While White discusses the issue at some length (especially in the book), a contrary instance might be Phys. $\Theta$ 8, 263b9-264a6. I will not, however, try to follow out this difficult question any further. I may also note that the above-mentioned LINNEBO, SHAPIRO, HELlman (2015) claims that "in the Aristotelian setting" some form of connectedness "is all the 'completeness' one can ask for" (p. 229).
} 
mereological parthood and topological connectedness is mathematically rich, ${ }^{21}$ and Aristotle's work may offer some reflections in this direction, the concept of connectedness itself is too weak to be of any help in elementary geometry. Each of the two "circles" in Elements I, 1, may well be topologically connected but their intersection point still be missing (think of two open rings).

A last point that should be emphasized concerning the mathematical use of Aristotle's definitions of continuity is that the interplay between a conception of continuity as, on the one hand, a relation and, on the other, a monadic property also had an important impact on the geometrical theory of intersections. As a matter of fact, without considering continuity in terms of relations, it would be impossible to establish the existence of the intersection between two figures, since from monadic premises such as "Circle $\alpha$ is continuous" and "Circle $\beta$ is continuous" there would be no way to conclude "Point $C$ exists". ${ }^{22}$ In late antiquity, the Middle Ages and the early modern era, it was quite common to see a geometrical magnitude defined as a continuous quantity, without further qualification or explanation and without any reference to a theory of relations. In such formulations the possibility of actually employing continuity in a geometrical proof was simply lost.

Aristotle's relational conception of continuity avoided the pitfalls involved in a monadic conception of this latter. Yet, Aristotle's own syllogistic does not allow for a treatment of relations; there was, therefore, no way, in antiquity, to implement continuity as a relation into a deductive system. This is, of course, a wider historical problem and it can be said that since a logic of relations was not developed in antiquity, therefore any deduction concerning continuity was left unexpressed in the geometrical proof (and possibly assumed through inspection of the diagram). The lack of such a logic of relations, in turn, may have been rooted in a general metaphysical world-picture that took individual substances and their properties to be the only existing beings. Such a world-picture would only alter with the advent of the early modern age, when relations began to be thematized as independent entities, when a specific logic of such independent entities was first conceived of, and when space, as a system of relations (a structure), was introduced into both metaphysics and mathematics.

\section{\$3. The problem of continuity in the early modern age.}

In the early modern age, geometers became aware that Euclid's proof of Elements I, 1 presented a demonstrative gap of some sort, and, as a consequence, the theory of intersections first became an object of mathematical investigation. Their approach to the matter, however, was more pragmatic than theoretical, and they did not embark in attempting to provide a general definition of continuity that could have been employed in geometry. They opted for the easier way to add a few ad hoc axioms to the principles of

\footnotetext{
${ }^{21}$ The entire field of mereotopology is devoted to exploring the connections between the notions of part-whole and continuity. In this field of study the concept of topological connectedness is often used as the main bridge between the two disciplines. For an introduction to the subject, see VARZI (1994); COHN, VARZI (2003); and PRATT-HARTMANN (2007).

${ }^{22}$ This very neat observation is made by FRIEDMAN (1992, pp. 60-61).
} 
Euclid's Elements, that could bridge the gap in the proof of Elements I, 1 (and cognate propositions). These principles are still in use in today's axiomatizations of elementary geometry, where they are called the Line-Circle and the Circle-Circle intersection principles:

If a straight line has one point inside a circle, the line will meet the circle.

If one of two circles has one point inside the other and one point outside it, the two circles will meet.

Such principles are in fact sufficient to ground the whole theory of intersections in elementary Euclidean geometry, and avoid to make any reference to the notion of continuity. ${ }^{23}$

The first instance of such principles is probably to be found already in Oronce Fine's Protomathesis from 1532, who added similar axioms in order to give a gapless proof of Elements I, 1. In the following century, however, the use of this kind of intersection axioms became widespread, and we find similar principles thematized and discussed in the essays on the foundations of geometry by Claude Richard (1645), Blaise Pascal (1655), Giovanni Alfonso Borelli (1658), Caspar Schott (1661), Gilles Personne de Roberval (1673-1675) and others. ${ }^{24}$

Despite the fact that such authors did not attempt a general definition of continuity, some of them justified the newly-introduced intersection axioms by stating that they derive from the fact that the geometrical figures themselves (such as the circles in Elements I, 1) are continuous - in some unspecified sense. This was a common view at the time: we may not possess a good definition of all the elementary geometrical notions, but we can make up for them by adding axioms that operationally characterize such notions. In a similar vein, for instance, several geometers of the $17^{\text {th }}$ Century claimed that no good definition of a straight line had ever been given, but that a few axioms about straight lines (that there is a straight line between two points, that two straight lines do not enclose a space, etc.) were sufficient to safely employ this notion in geometry. Continuity, then, could have been supplanted by the Line-Circle and Circle-Circle intersection axioms, without engaging in the most difficult task of giving an exact definition of this notion.

Leibniz was well aware of these developments. He had studied and annotated Borelli's book, and employed Schott's principles in his geometrical researches. Most importantly of all, he had had the chance, during a visit to Paris, to read the manuscript notes by Pascal on the foundations of geometry and to study Roberval's papers on the same subject. ${ }^{25}$

Nonetheless, Leibniz's approach to continuity was radically different from anything that had been attempted before and his work on the subject, however tentative and imperfect it may be judged to be, opened a new era in the examination of this notion in mathematics. The main revolution, compared to those preceding theorizations, consisted in the fact that Leibniz now attempted a directly mathematical definition of continuity (in

\footnotetext{
${ }^{23}$ See HARTSHORNE (2000, pp. 104-16).

${ }^{24}$ For a quick survey of these editions of Euclid and their intersection axioms, see DE RISI (2016). I am expanding on the subject, detailing the various early modern solutions, also in my DE RISI (forthcoming B).

${ }^{25}$ See DE RISI (2015).
} 
general) rather than being content to accept a number of local and ad hoc statements which merely fixed up the gaps in the Euclidean proofs.

There are a number of reasons for this radically new attitude. Leibniz's studies on the Calculus are clearly the main driving force behind his investigation of continuity, since they required a general understanding of this notion. General philosophical concerns were also at stake, because Leibniz was able to capitalize upon his mathematical discussions of continuity, which had arisen out of the Calculus, turning them into a whole range of metaphysical principles of continuity, which may have been a little vague in their formulation but still had, in his eyes, a strong heuristic value for philosophical investigations. Mathematical epistemology also played an important role here. Leibniz's foundational project in geometry, in fact, relied not so much on the introduction of new axioms as on their progressive elimination by proofs. His ideal geometry was a science without axioms: a science which would be founded upon the Principle of Contradiction alone and which would show that pure logic is powerful enough to establish all the truths of Euclidean geometry. In pursuit of this aim, he wanted to prove continuity and intersections rather than merely assuming these latter on the basis of special principles. In this sense, the continuity principles of Pascal, Borelli, or Roberval seemed to him to be an intermediate stage in the process of perfection of the science; they represented the realization that something was missing in the ancient proofs, as well as an ad hoc way of "fixing up" these latter that still needed, however, to be fully worked out by "proving" these ad hoc statements from the geometrical definitions.

It should be added that, in the few years that elapsed between the works of Richard and Borelli and the investigations of Leibniz, geometry had been extended to a far wider domain of objects than those dealt with in Euclid's Elements. Whereas a foundational solution provided for the geometry of the Elements might still have been conceived to be applicable to a few other cases extending beyond the ambit of this latter (such as Apollonius's conic sections, or perhaps Descartes's algebraic geometry), it was clear that a discussion on continuity and intersections conducted at the end of the $17^{\text {th }}$ Century which aspired to ground the possibility of the new geometry emerging in this period could not possibly be restricted to the narrow domain of circles and straight lines alone. Leibniz's foundational studies, in particular, aspired to provide a foundation for the whole of mathematics, not just elementary geometry. He could not rest content with the "CircleCircle" or "Line-Circle" continuity principles and needed the full Dedekind completeness. In fact, in the many studies that Leibniz undertook on the text of the Elements and the foundations of Euclidean geometry, I have not been able to find any reference at all to $a d$ hoc axioms with which the theory of intersections might be grounded.

Nonetheless, before turning to his discussion on continuity, it should be remarked that something similar to a set of ad hoc axioms for intersections is to be found in Leibniz's symbolic studies on a new characteristica geometrica. These latter researches were aimed at producing a formal system, similar to Cartesian algebra, which, rather than expressing quantities and magnitudes, would directly express points and geometrical relations. Leibniz began to work at developing such a logical system around 1679 and continued to do so for many years, without, however, ever achieving any real breakthrough. In this formal system, Leibniz could express geometrical points by means of letters, situational relations by means of a functional symbol, and other geometrical relations among situated elements, such as congruence, similarity or equality, by means of other operational symbols. A kind of 
universal quantifier, expressed by a mark over a letter, completed the set of symbols for most elementary applications. To give an idea of such a symbolic system, a sphere in space is here expressed as $\underline{X}: A . B \simeq A . X$, meaning that the sphere is the set of
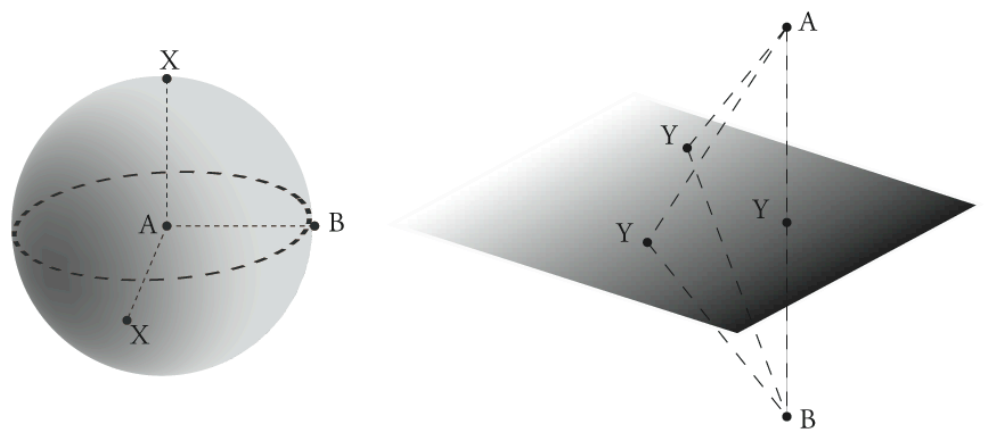
all points X's such that the situational relation of $\mathrm{A}$ to $\mathrm{B}$ is congruent to the situational relation of $\mathrm{A}$ to $\mathrm{X}$, the latter condition implying that the distance between $\mathrm{A}$ and $\mathrm{B}$ is equal to the distance between $\mathrm{A}$ and all X's. A plane in space, on the other hand, is expressed by $\underline{Y}: A . Y \simeq B . Y$, meaning that it is the collection of points Y's that are at the same distance from the two points A and B. Leibniz thought that the whole of geometry should be expressed in such a symbolic system, which he called a characteristica geometrica propria, that is to say, a system directly representing geometrical objects and relations, without any admixture of numbers or of extraneous functions and relations such as those of ordinary Cartesian algebra. Leibniz's treatment of intersections in this system is given axiomatically and not by a general definition of continuity. In fact, in his first attempts at such a characteristics, he basically accepted a few symbolic axioms in order to guarantee the existence of the points of intersection required. Thus, given two planes $\underline{Y}: A . Y \simeq B . Y$, and $\underline{Y}: A . Y \simeq C . Y$, these will intersect in the straight line $\underline{Y}: A . Y \simeq B . Y \simeq C . Y$, obtained by composing the two symbolic expressions; and the two spheres $\underline{X}: A . C \simeq A . X$ and $\underline{X}: A . B \simeq A . X$ would intersect in the circle $\underline{X}$ : A.B.C $\simeq$ A.B.X, obtained from the previous expressions by a different composition rule. Leibniz gave similar combinatorial rules to show that two straight lines meet in a point, and two circles meet in two points. ${ }^{26}$ It is clear that these very particular cases of intersections cannot be easily generalized to other figures, and that, while dispensing with a notion of continuity, they are to be considered largely insufficient to ground geometry. Leibniz never attempted to justify the combinatorial axioms themselves and it is not easy to fathom how they could have been proven from more elementary combinatorial assumptions (or from the Principle of Contradiction). In later years, as we will see, Leibniz also attempted to formalize his notion of continuity in the language of the characteristica geometrica.

\section{\$4. Leibniz’' early studies.}

We now turn to Leibniz's studies on the notion of continuity, in so far as they were aimed at defining a geometrical continuum and therefore grounding a general theory of intersections in elementary geometry. These Leibnizian researches often took their lead from the definitions of continuity offered by Aristotle, reworking them in just a few details, or simply reinterpreted the terms of the definition, giving to the old words a completely new meaning. By this progressive adjustment of the old definition, Leibniz finally achieved

\footnotetext{
${ }^{26}$ The rules may be easily extended to any number of dimensions and, even if Leibniz did not pursue this line of reasoning, he was applauded by Grassmann for having found such general formulas (see GRAßMANN 1847).
} 
a new, mathematical definition of continuity (as completeness) which far surpassed any Aristotelian notion.

As a young man, Leibniz often repeated, even ad literam, the Aristotelian definition of continuity and contiguity. ${ }^{27}$ Even in these early years he already attempted some reinterpretations, and sometimes addressed the classical problems of such a definition. In 1670 , for instance, attempting to ground a theory of the composition of the continuum by indivisibles (something that Aristotle had denied), he asserted that such indivisibles had to be non-extended yet nonetheless composed of parts, so that they could touch each other in some parts and (following the Aristotelian definition) constitute something continuous. ${ }^{28}$

Later on, he rejected such a view, and attempted to define continuity as the togetherness of the boundaries of two bodies in the same place (as Aristotle had done in the case of contiguity), trying to explain the difference between continuity and contiguity by the forces which impel such bodies. In this way, he attempted to replace Aristotle's metaphysical reference to unity by a physical explanation. He discarded, however, this theory as well in the following years. ${ }^{29}$

Leibniz also attempted to offer a less physical and more geometrical distinction between continuity and contiguity, by accepting a Scholastic development of the Aristotelian notion of contiguity, and defining contiguous bodies as bodies that are nondistant to one another:

Contiguous things are those between which there is no distance. ${ }^{30}$

\footnotetext{
${ }^{27}$ See for instance his first essays on physics written in Paris, the Propositiones quaedam physicae from 1672: "Et c'est la difference entre les choses contiguës, qui se touchent seulement dont les extremitez sont ensemble, et entre les choses continues, qui se presentent, dont les extremitez sont devenuës un. Comme Aristotle meme l'observe" (A VI, 3, n. 2, p. 8). At the end of his Parisian stay, in the great dialogue Pacidius Philaleti, he discussed the whole matter once again (proposing his peculiar solution to the problem of the composition of the continuum), and mentioned once again Aristotle's definition and distinction: "Memini Aristotelem quoque Contiguum a Continuo ita discernere, ut Continua sint quorum extrema unum sunt, Contigua quorum extrema simul sunt" (A VI, 3, n. 78, p. 537).

${ }^{28}$ See the Fundamenta praedemonstrabilia of the Theoria motus abstracti, in A VI, 2, n. 41, p. 264.

${ }^{29}$ See A VI, 3, n. 4, p. 95-96, from 1672. The theory was refuted in the Pacidius Philaleti from 1676. A fine account of Leibniz's early theory of the cohesion of matter and of this latter's relation to his later views on continuity is to be found in LEVEY (1999).

${ }^{30}$ The passage comes from a 1672 fragment on forces and physical bodies: "Consistentia corporum est quantitas virium necessariarum ad solutionem continuitatis. Continua sunt contigua cum aliqua consistentia. Contigua sunt inter quae distantia nulla est" (A VI, 3, n. 4, p. 94; translated in ARTHUR (2001, p. 19). It is not easy to make out whether, and if so how, Leibniz's conception of contiguous, undistant points was accepted by him in mathematics. We may mention that, in 1698, Leibniz stated very clearly to Johann Bernoulli the impossibility of giving two points that are infinitely close or next to one another: "...non tamen sequitur duo puncta dari sibi infinite vicina, et multo minus dari sibi proxima” (GM III, p. 536). In 1705, however, we find him writing to De Volder that "we cannot conceive of three continuous points in a straight line; but two may be conceived of: the extremities of two straight lines from which the continuous whole results" ("Tria puncta continua in eadem recta concipi non possunt. At duo concipiuntur: extremitas unius rectae et extremitas alterius rectae ex qua constat idem totum", in GP II, p. 279). The apparent oscillation in his views here may perhaps be accounted for by saying that the passage addressed to Bernoulli concerns ideal objects, while the passage to De Volder deals with the real world. In any case, the notion of contiguity was still there at the end of Leibniz's life. We may notice that the terminology of points that are next to one another is clearly derived from the indivisibilist scholastic tradition. We find similar passages, for instance, in
} 
In other writings, in fact, he explicitly corrected the Aristotelian notion:

From which one understands that the boundaries of contiguous things are not only "not one" but also "not together".

In some mature writings Leibniz claimed that two contiguous bodies are separated by an "unassignable" space, that is to say, by a space smaller than any given space. The use of quantifiers in these last statements is, however, a little uncertain. On the one hand, if we accept the Archimedean Axiom, the distance in question here seems to have necessarily to remain finite, even though it is vague (inasmuch as it is not assignable) and Leibniz may in fact have endorsed this view (he took it to be further evidence that bodies are not completely real, and therefore an argument in favour of phenomenalism). Nonetheless, it is not clear how such a notion could be formalized in geometry. ${ }^{32}$ On the other hand, it is possible that these unassignable spaces are to be regarded as actually infinitesimal vacua between parts of matter. They would thus tend to push Leibniz toward a non-Archimedean geometrical system. ${ }^{33}$ In fact, there seems to be no viable topological notion of an immediate contact of two boundaries in classical (Archimedean) mathematics. A space that would allow such contact would not be normal (in the technical topological sense, i.e. the

J. WYCLIF (1893, vol. 3, p. 30): "nam est dare duo puncta immediate, ut patet de corporibus tangentibus, sic ubicaciones vel situaciones eorum sunt immediate", quoted in ROBERT (2009, p. 155 n. 116).

31 The passage comes from Leibniz's 1693 remarks on the celebrated book by Libert Froidmont, the Labyrinthus sive de compositione continui (1631). These remarks of Leibniz's have been published as ALCOBA (1996), but they have been recognized as reading notes to Froidmont only by PALMERINO (2016). Our quote is from p. 194 of Alcoba's paper: "Unde etiam intelligitur contiguorum extrema non tantum non esse unum, sed ne quidem esse simul". Some remarks on the relations between Leibnizian and Aristotelian views on continuity may be found in CROCKETT (1999).

${ }^{32}$ It should be noticed that already the above-mentioned book by Froidmont had claimed that the notion of contiguity could not be expressed by a contact or overlapping of boundaries, but rather only by a compenetration of indeterminate parts. Froidmont applied this solution to both physical and mathematical contact. It is possible that such a theory could be formalized making use of a formal notion of vagueness, but I will not further pursue this line of thought here, since Leibniz was to abandon such a view in his mature years. On Froidmont's theory of the continuum, see also PALMERINO (2015).

${ }^{33}$ The above-mentioned passage from Leibniz's reading notes on Froidmont clearly represents an opening toward non-Archimedean considerations (see pp. 194-96 of the quoted paper by ALCOBA 1996). After having defined contiguity as undistant contact, Leibniz gives the example of a set of smaller and smaller spheres, one inside the other, which are tangent at a single point. Take for instance three spheres $\alpha, \beta, \gamma$, such that $\gamma$ (the smaller one) is in $\beta$, which is in $\alpha$ (the larger one), while all three of them are tangent at point $T$. Leibniz says that the smaller, more internal sphere $\beta$ can touch the larger external sphere $\alpha$ at point $T$, but the third even smaller sphere $\gamma$, inside the second $\beta$, does not touch the first larger sphere $\alpha$ (because the second one is interposed between them), even though it passes through point $\mathrm{T}$ as well. He concludes that if we take an infinity of such concentric tangent spheres, we will have a "full point" (punctum plenum), i.e. $T$, which contains an infinity of distinct and ordered points, and which therefore cannot be distinguished from an unassignable segment. In the following pages, Leibniz is naturally brought to consider sheaves of parallel, undistant straight lines, and he finds them more problematic. His notes conclude in a somehow inconclusive fashion, a few pages later, by stating that perhaps one has to deny the existence of actually infinitesimal lines. 
sense of not satisfying axiom of separation $\left.\mathrm{T}_{4}\right)^{34}$ and such spaces cannot be metrized: should we accept that two boundaries might be at no distance at all from one another, the notion of distance would simply disappear. Indeed, even if we could manage (with some difficulty) to formalize such a notion of contact in mereology (as the Aristotelian and Leibnizian terminology of parts and wholes directly suggests we might), the resulting mereological structure could not be strengthened into a metrical one, and would therefore be useless in classical Euclidean geometry. ${ }^{35}$

The notion of contiguity, however flawed from a mathematical point of view, allowed Leibniz to formulate in the Parisian years (1672-1676) a theory of matter that he endorsed (with small modifications) for the rest of his life. Leibniz denied the existence of atoms and accepted the infinite divisibility of matter. He also denied that bodies are actually divided, to infinity, into points (because he denied that points could possibly compose the continuum). Instead, he endorsed the (quite non-Aristotelian) view that bodies are infinitely divided in actu, but in a purely "syncategorematic" way. This latter notion aimed at expressing the idea that there is no final element in the division of matter (i.e. no point), even though there are more divisions of bodily parts than can possibly be expressed by any finite number. A useful comparison may be made here with an infinite series (a mathematical tool that Leibniz was gradually mastering during his Parisian years), in which there is no final element (i.e. no actual infinitesimal term), even though there are more terms belonging to the series than any finite number can possibly express, and these terms draw progressively closer and closer to zero. ${ }^{36}$ Leibniz claimed, therefore, that matter is not divided, all the way down, into points, but is rather divided to infinity following a certain succession of smaller and smaller corpuscles, such that each of these corpuscles is always further divided in some (but not all) possible ways. In mathematical terms, we might say that the system of boundaries in matter is dense in this latter. ${ }^{37}$

\footnotetext{
${ }^{34}$ The $\mathrm{T}_{4}$ separation axiom states that given any two closed sets, there are two disjoint open sets each containing one of the closed sets. While the topological subtleties involved in such a proposition could not possibly be grasped in the $17^{\text {th }}$ Century, the intuitive meaning of such a principle is that between the boundaries of two figures there must be "space enough", thus forbidding contiguity in the sense of "immediate contact". Roberval, in his Eléments de géométrie has a similar postulate, stating that "Quelque grand que soit un solide fini et terminé, l'esprit s'en peut encore représenter un plus grand et meme de sorte que le plus grand contiendra entièrement le moindre et le surpassera de toutes parts, le petit étant une portion du plus grand. On peut aussi entendre que ces solides inégaux soient entièrement séparés de lieu" (Book I, Post. 7; ed. JULLIEN 1996, p. 99).

${ }^{35}$ For a few difficulties involved in capturing the notion of contiguity in a mereological setting with some topological elements (but no metrics), see, for example, CASATI, VARZI (1999); and BENNETT, DÜNTSCH (2007). See also the above-mentioned HELlmAN, SHAPIRO (2013), which offers an axiomatization for linear regions without points that allows for a kind of contiguity (i.e. "adjacency"). In this context, however, to be contiguous only means that no region is interposed between two other regions-which are therefore "adjacent" to one another. It should be noted that this notion of contiguity is much weaker than the Aristotelian one (not to mention the one recurring to a vanishing distance). Aristotle himself called "consecutive" two parts such that between them there is nothing of the same genus (two houses are consecutive to one another if no further house is between them, but they need not to be contiguous; the same applies to two lines separated by something which is not a line): see ARIST. Phys. E 3, 226b35-227a5.

${ }^{36}$ See for instance S. LEVEY (1998), ARTHUR (2001, 2013, and 2018).

${ }^{37}$ The most important text from the Parisian period on this subject is the dialogue Pacidius Philaleti (A VI, 3, n. 78, pp. 529-71) but this cluster of ideas is restated several times in the mature writings. On Leibniz's notion of continuity in his early and Parisian years, see BEELEY (1996); ARTHUR (2001), which offers a rich
} 
A first consequence of Leibniz's thesis of the actually infinite division of bodies was that he began to regard continuous magnitudes not as faithful representations of real bodies (as Aristotle would have held them to be), but rather as abstract and ideal objects employed in mathematics by means of which we can attempt to model the (actually discontinuous) world, but only up to a certain degree of approximation. ${ }^{38}$ This prompted him, in the 1680 s, to develop a more formal definition of continuity for mathematical objects, one which rested upon the notion of indeterminacy. While real bodies, he argued, are divided to infinity through a system of nested boundaries which separates them into smaller and smaller contiguous particles, an ideal, continuous extension is characterized by the absence of such actual divisions and is susceptible of being divided in whatever way the mathematician may wish to divide it.

This Leibnizian definition recurs extremely frequently in his mature works. Although it was slightly reformulated from time to time, the basic definitional system is the following: a continuum is a whole the parts of which are indefinite and have a reciprocal position with respect to one another. ${ }^{39}$ The parts are indefinite because the continuum is not actually divided and no system of boundaries is given. In this respect, Leibniz is simply restating, as a definitional property, the old Aristotelian idea that a continuous whole is only potentially divisible: but he is applying this property of merely potential divisibility not to real things (which are, for him, not just potentially but actually divided) but rather to geometrical objects. He is thus mathematizing Aristotle's definition by limiting it to the domain of ideal entities. The further definitional requirement here - namely, that the parts of a continuous whole should have a position with respect to one another - is intended to exclude from the class of continuous wholes both numbers and intensive magnitudes (heat, force, etc.). Sometimes Leibniz simply states that a continuous whole has partes extra partes, where the preposition extra is intended to mark the positional nature of the relation. ${ }^{40}$

It should, lastly, be mentioned, that Leibniz, like many other mathematicians and philosophers before him, also happened to characterize, from time to time, continuity as density. He saw the possibility of finding new terms between any two terms of a set as a mark of continuity. ${ }^{41}$ Nonetheless, it is in this connection that we find his first true breakthrough.

anthology of Leibniz's writings on the topic, accompanied by a thoughtful and extensive commentary; and LEVEY (2003), which also discusses at some length the notion of contiguity and approaches Leibniz's later solutions to fractal geometry.

${ }^{38}$ See GARBER (2015).

${ }^{39}$ Cf. this passage from 1680-1684: "Continuum est totum cujus partes indefinite assumi possunt, et habent positionem inter se. In quo differt ab unitate, et a toto intenso, ut potentia, calore” (A VI, 4A, n. 97, p. 390). Several similar definitions, however, may be found among Leibniz's papers.

${ }^{40}$ See, for example, C 438: "Continuum est totum cujus partes sunt extra partes, et indeterminatae. Nempe extra partes, id est separatim perceptibiles, ut distinguatur à Graduali toto, cujus partes se penetrant; cum aestimatur intentio qualitatum; Indeterminatae vero sunt partes continui, quia nullae jam sunt assignatae, sed pro lubitu assignari possunt, ut distinguatur à contiguo”.

${ }^{41}$ Already in 1671, Leibniz qualified the common definition of continuity as density by stating that a continuous whole is a whole such that between any two parts of it one can find a further part, which is, of course, a different property than simple density (because it quantifies over parts rather than points): "Continuum est Totum inter cuius partes quaslibet interjectae sunt aliae partes ejusdem" (De natura rerum corporearum, A VI, 2, n. 452, p. 307). We will see that this was to be an important feature of Leibniz's mature 
In fact, Leibniz's theory of the infinite division of matter is mathematically very relevant in so far as it may hint to a distinction between density and continuity. Leibniz, in fact, was obliged to attempt to characterize an infinite sequence of elements (i.e. the boundaries of bodies) within the continuum of space, which is dense in this latter but does not exhaust it (since, in addition to the boundaries, there is also matter in space). ${ }^{42}$ This is a development of the utmost importance for a mathematical understanding of continuity and the first step toward the possibility of defining completeness in the modern sense. I was not able to find any trace of a distinction between continuity and density in any author preceding the work of Leibniz (and, truth be told, not even in essays written many decades after Leibniz's death). Leibniz's very peculiar conception of an actual, syncategorematic infinite, which found no sequel among his successors, seems to be the source of this important step forward.

The clearest passage stating a mathematical distinction between density and continuity, however, was written by Leibniz much later than his first introduction of a syncategorematic infinity. It is to be found in his mature treatise Specimen geometriae luciferae, which is the very essay in which Leibniz's new conception of continuity as completeness was (as we shall see) to make its first appearance. The Specimen, a text probably written in the mid-1690s, ${ }^{43}$ is one of Leibniz's most daring explorations of the foundations of geometry and collects together a number of new and outstanding ideas in mathematics. In a section of it, Leibniz discusses continuous geometrical transformations and gives the example of the transformation of a circle into a family of ellipses having the same area. He says that the set of ellipses thus produced may be regarded as continuous, and that we may, in fact, give a geometrical structure to this set by constructing a solid body the sections of which are the ellipses of the set. Such a solid body, composed by the ellipses, would be itself continuous:

notion of continuity. In other texts, however, he was not so careful and simply referred to finding points between any two given points.

${ }^{42}$ We may note that Clarke (and possibly Newton himself, who was behind several of Clarke's observations in the famous correspondence with Leibniz) objected to this theory of matter by saying that an infinity of divisions in bodies would result in bodies disappearing: "If therefore carrying on the division in infinitum you never arrive at parts perfectly solid and without pores, it will follow that all bodies consist of pores only, without any matter at all—which is a manifest absurdity" (Clarke's Fourth Reply, postscript; in ROBINET 1957, p. 116). The argument seems to conflate density with continuity.

${ }^{43}$ The dating of the Specimen is extremely difficult, since there are no external (i.e. material) criteria for it, and one is forced to rely on internal content only. I accept the dating proposed by the Leibniz-Archiv, since this concords well with the idea that it is a development of Leibniz's thought from the very similar essay Hic memorabilia... (in DE RISI 2007, pp. 586-87) which we will discuss below and which is most likely also to be dated to around the mid-1690s (there might be taken as possible proof of this the use of the rare term "epharmostica", which appears in this text and then in Leibniz's fragment De ordinatione cognitionum in A IV, 6, n. 68, p. 500, a text dating from not earlier than July 1695; and in another couple of essays, such as the Euclides in definitione Diametri Circuli in LH XXXV, XII, 2, Bl. 107, and the Analysis didactica in LH IV, 7C, bl. 139-145, also surely dating from the 1690s). Moreover, the terminology employed by Leibniz in the Specimen is strictly connected with a Scheda on situation and extension (published in DE RISI 2007, pp. 58889), also dating from a period within that timeframe (cf. the use of the notion of congeneum). The Specimen would seem also to have been written after 1693, because it appears to display a development with regard to the notion of continuity as compared to Leibniz's reading notes to Froidmont (see above, note 31). 
We may conceive something as continuous not only among those things that exist at the same time, and in fact not only in space and time, but also in a transformation and in the aggregate of all states of a certain continuous transformation. For instance, if we assume that a circle is continuously transformed, and goes through all the species of ellipses preserving its magnitude, then the aggregate of all these states, that is to say of all the ellipses, may be regarded as continuous even if the ellipses are not in contact and do not exist together but one of them is produced by the other. We may, however, take a family of ellipses that are congruent to those obtained by the transformations, and compose a solid figure from all these ellipses, that is to say, a solid whose sections parallel to the base are all those ellipses taken in order. ${ }^{44}$

This is already a remarkable passage, for it shows that Leibniz was able to conceive of a solid as composed of "indivisible" surfaces. The continuity of such a solid seems to be guaranteed by the continuity of the transformation, which makes it possible to pick up all the ellipses (without any missing elements). In the immediately following passage Leibniz went on to state that, if we were to consider the transformations of a sphere into a family of spheroids, the outcome would be a four-dimensional continuous figure which, however, we would not be able to exhibit, "for in extension we do not have more than three dimensions". We might, however, express such a notion by employing other nongeometrical means (i.e. by exhibiting these extra dimensions using weight or speed, for example).

In any case, Leibniz says, the important point is that we may construct a (biunivocal, and continuous) correspondence between the family of ellipses and the points of a segment (the height of the solid thus composed). In the case of spheroids, their transformations into other spheroids of equal volume is not a one-parameter transformation, and therefore we should place them not in correspondence with a segment but rather with the points of a plane (for a two-parameter transformation), or a solid body, or a $n$-dimensional object. From a mathematical point of view, Leibniz seems to be remarkably close to the modern idea of a continuous fibration of a manifold.

He goes on to give some examples of these fibrations and then concludes by saying that it is easy to find a family of figures in which, between any two of them, we may always find another (given a rule for interpolation), these figures not, however, being continuous because they do not exhaust the points of the parameter (the segment, or plane, etc.). In this way, he actually manages to provide a mathematical discussion of the difference between density and continuity:

Thus we understand the nature of a continuous transformation and that it is not enough, in order for such a continuous transformation to be said to obtain, that,

\footnotetext{
${ }^{44}$ The text comes from GP VII, p. 285: "Possumus continuum aliquod intelligere non tantum in simul existentibus, imo non tantum in tempore et loco, sed et in mutatione aliqua et aggregato omnium statuum cujusdam continuae mutationis, v. g. si ponamus circulum continue transformari et per omnes Ellipsium species transire servata sua magnitudine, aggregatum omnium horum statuum seu omnium harum Ellipsium instar continui potest concipi, etsi omnes istae Ellipses non sibi apponantur, quandoquidem nec simul coexistunt, sed una fit ex alia. Possumus tamen pro ipsis assumere earum congruentes, seu componere aliquod solidum constans ex omnibus illis Ellipsibus, seu cujus sectiones basi parallelae sint omnes illae Ellipses ordine sumtae".
} 
between any two states, it be possible to find an intermediate one: it is possible, in fact, to conceive some progressions such that there are always further interpolations, and nonetheless they must not be conflated with a continuum. ${ }^{45}$

Even though the difference between continuity and density is possibly never stated again with this degree of clarity, it seems that Leibniz never fell back behind the point of this important breakthrough. ${ }^{46}$ In fact, the Specimen is the first essay in which Leibniz is able to formulate his last, and most fully perfected, definition of continuity and it is entirely possible that such a novel definition arose together with, and as a result of, the clear conceptual distinction between continuity and density.

We should finally remark that the continuity of the figures composed by the fibrations seems to derive from the continuity of the parameter itself; that is to say, this continuity appears to be derived from the biunivocal correspondence with the points of a segment and the continuity of the segment itself. In this connection, Leibniz's distinction between density and continuity seems to offer some indication of the fact that the points of the segment are in some sense the "totality" of all possible points. In a still informal sense, Leibniz is treating the segment (i.e. the parameter, or the basis of the fibration) as a complete set of points.

This idea also resonates with some other considerations that Leibniz engaged in elsewhere with regard to transformations. We have already mentioned that Leibniz possessed a very good analytic definition of a continuous function, given by a kind of $\varepsilon-\delta$ formalism. While such a definition is far from sufficient to define any kind of continuity of space, Leibniz had also formulated a continuity principle based on his notion of a continuous function, stating that in continuous things the last element of an infinite sequence may be treated just the same as the previous ones. ${ }^{47}$ This rather vague "postulate"

\footnotetext{
${ }^{45}$ Here the original passage: "Itaque ex his etiam mutationis continuae natura intelligitur, neque vero ad eam sufficit, ut inter status quoslibet possit reperiri intermedius; possunt enim progressiones aliquae excogitari in quibus perpetuo procedit talis interpolatio, ut tamen non possit inde conflari aliquod continuum..." (GM VII, p. 287).

${ }^{46}$ This point may be recognized in several quite indirect ways. One of them is that, in a few essays written after the Specimen, Leibniz states that the infinite divisibility (i.e. density) of a straight line may be inferred by its definition as a self-similar line (i.e. a line, each segment of which is similar - in mathematical terms - to the whole). This deduction of density is repeated in the Nouveaux Essais, II, XVII, $\$ 3$, from 1704 (A VI, 6, n. 2, p. 158); in a letter to Des Bosses dated February $14^{\text {th }}, 1706$ (GP II, p. 300); in another letter to Wolff from 1711 (BW, p. 141), and in the essay In Euclidis $\pi \rho \tilde{\omega} \tau \alpha$ from 1712 (GM V, p. 206). In none of these passages, however, does Leibniz state that the straight line is continuous for this very reason. He seems to be aware that through his argument from similarity he may only derive a weaker property than continuity. Nevertheless, it must be noted that, in a very late letter to Des Bosses dated May 29 ${ }^{\text {th }}, 1716$, Leibniz still claimed that if between any two points of an extension there is another point (i.e. if the set of points is dense), then the extension is continuous, thus relapsing into the common view: "Eo ipso, dum puncta ita sita ponuntur, ut nulla duo sint, inter quae non detur medium, datur extensio continua" (GP II, p. 515).

${ }^{47}$ Such a principle is stated, for instance, in a letter to Christian Wolff that Leibniz published in the Acta eruditorum from 1713: "Atque hoc consentaneum est Legi Continuitatis, a me olim in Novellis Literariis Baylianis primum propositae, et Legibus Motui applicatae: unde fit, ut in continuis extremum exclusivum tractari possit ut inclusivum, et ita ultimus casus, licet tota natura diversus, in generali lege caeterorum, simulque paradoxa quadam ratione, et ut sit dicam, Figura Philosophico-rhetorica punctum in linea, quies in motu, specialis casus in generali contradistincto comprehensus intelligi possit, tanquam punctum sit linea infinite parva seu evanescens, aut quies motus evaneseens, aliaque id genus, quae Joachim Jungius, Vir
} 
(as Leibniz also called it) might be interpreted in geometrical terms as stating that a continuous space should contain the limit of any (converging) sequences in it, since otherwise this limit would not be an extremum inclusivum but rather an extremum exclusivum (i.e. a limit external to the set) - something which is ruled out by the hypothesis of continuity. With such a (rather generous) interpretation of Leibniz's principle, one might attempt to claim that continuity is here defined as completeness in WeierstrassCantor terms (existence of the limits of all converging sequences). ${ }^{48}$ Nonetheless, aside from the fact that Leibniz's words would thereby be being stretched far beyond their immediately evident meaning, it should be noted that Leibniz never applied such a principle to space or to magnitudes. He clearly considered it a heuristic rather than a constitutive principle, and as something that may happen (thanks to God's good will, which should play no role in geometry) in some continuous things-in short, a contingent characterization of continuity rather than a definition of it. In particular, Leibniz never attempted to employ such a definition of continuity to prove the intersection of lines. We will, therefore, abandon this line of research, since (however promising one might wish to consider it to be) it seems not to have been intended by Leibniz as a foundational approach to geometry. We rather turn now to the most mature results of these researches, that is to say, to Leibniz's final definition of continuity as completeness.

\section{\$5. Leibniz's definition of continuity.}

The final stage of Leibniz's investigations into continuity began around 1695 and is to be found in the masterwork on geometry of his middle years, the Specimen geometriae luciferae. ${ }^{49}$

Leibniz's most mature definition states (loosely paraphrasing) that a continuous whole is a whole such that its parts overlap in a boundary, which is not itself a part. It is remarkable how close this Leibnizian definition is to the Aristotelian one in terms of contact and identification of the boundaries of two bodies; nonetheless, the understanding of the terms involved is quite different and by this time several centuries of philosophical work had left their sediments upon the old Aristotelian definition. For example, the reformulated definition now no longer refers to some given parts, but rather to all the possible parts of a whole. The parts may now overlap one another-something that was not

profundissimus, toleranter vera appellasset, et quae inserviunt plurimum ad inveniendi artem, etsi meo judicio aliquid fictionis et imaginarii complectantur, quod tamen reductione ad expressiones ordinarias ita facile rectificatur, ut error intervenire non possit: et alioqui Natura ordinatim semper, non per saltus procendes legem continuitatis violare nequit" (now in GM V, p. 385). The passage has been recently commented upon by JESSEPH (2015), and GLEZER (2017, pp. 50-55). A similar, very clear statement of the same principle is also to be found in an unpublished essay written by Leibniz around the Historia et origo calculi differentialis: "Assumo autem hoc postulatum: Proposito quocunque transitu continuo in aliquem terminum desinente, liceat ratiocinationem communem instituere, qua ultimus terminus comprehendatur" (now in the appendix of LEIBNIZ 1846, p. 40).

\footnotetext{
48 This thesis has been advanced by ANAPOLITANOS (1990).

49 The only essays known to me that deal with these Leibnizian texts on continuity are GIUSTI (1990) and LEVEY (1999), which, however, discuss them only in relation to the standard (Aristotelian) notion of connectedness.
} 
possible according to the Aristotelian definition. We do not, however, need to insist on these (and many other) subtle philosophical variations, since Leibniz's massive advance in this field clearly consists above all in his having given a mathematical definition of the terms employed in this concept of continuity (parts, boundary, etc.). Such a definitional apparatus is to be found, indeed, in the Specimen itself. But the way is in fact prepared for it in innumerable essays and fragments from the late 1680s and early 1690s which set the stage for the new definition. ${ }^{50}$

The starting point is the reworking of the notion of a part. We need, then, to delve a little way into Leibniz's mereology. ${ }^{51}$ It should be noted that Leibniz generally conceived of wholes and parts as collections (or sets, or aggregates) of elements-possibly, of points. Leibniz's mereology, therefore, at least as far as geometry is concerned, is a kind of mereology in a naïve set-theoretical environment. ${ }^{52}$

Leibniz defines a part as something that is in (relation of in-esse) the whole and is homogeneous with the whole. To be in the whole means simply that the part is a proper subset of the whole and Leibniz never considers the whole itself as one of its parts. In some other texts Leibniz employs the equivalent notion of in-existere. ${ }^{53}$ The notion of

\footnotetext{
${ }^{50}$ In fact, Echeverría has found two Leibnizian fragments from 1679, in which Leibniz plainly states that a whole is continuous if its parts have a boundary in common: "Continuum est cuius partes habent terminum communem" (LH XXXV, I, 11, Bl. 54v., and similarly in LH XXXV, I, 12, Bl. 4r.; transcribed in ECHEVERRÍA 1980, vol. 2, pp. 293 and 329; also mentioned in ECHEVERRÍA 1990). In these fragments, however, the most important qualification is missing: namely, that stating that those parts must have in common only a boundary. As they stand, in fact, they seem to mean that, in order for there to be continuity, it is sufficient that the parts of the whole should have a boundary in common; nonetheless, they might have in common also an entire part. The notion is still naïve and seems to be driving at some idea of connectedness. No geometrical consequences, in any case, are drawn from this definition, and Leibniz did not attempt to employ it to prove Elements I, 1 or any other Euclidean proposition in need of a continuity assumption. In short, such fragments may just reflect the old Aristotelian definition of continuity.
}

${ }^{51}$ A fuller account of Leibniz's rather complex mereological thought is to be found in the essay by Massimo Mugnai in this volume, which deals especially with the mereological considerations in Leibniz's Specimen geometriae luciferae, which is also the most important text for his definition of continuity.

${ }^{52}$ We will deal further with these complications (i.e. the interaction between set-theoretical and mereological elements) below. In a sense, the conceptual setting might be considered analogous to the one described in the celebrated D. LEWIS (1991). I employ here freely the word "set" or "collection", whereas Leibniz, of course, had no axiomatic approach to the notion of a set. It should be remarked, though, that he was able to provide some rather abstract definitions of membership. In one of his writings, he said that if, from the fact that $A, B, C$ are posited, it immediately follows that $L$ is also posited, then $L$ should be considered to be the aggregate of $A, B, C$ (Inquirenda logico-metaphysica, in A VI, 4A, n. 210, p. 998). In such a situation, each of the $A, B, C$ is in $L$ (relation of in-esse). We should notice that Leibniz also defines the parthood relation by means of similar statements and that he probably did not make any exact distinction between mereological and settheoretical considerations. Nonetheless in the above-mentioned passage it seems clear that the aggregate $L$ cannot be entirely reduced to the three elements that compose it, since it is explicitly stated that it is a fourth object, distinct from these latter.

${ }^{53}$ Cf. for instance the Specimen geometriae luciferae, in GM VII, p. 274. This definitional system is recurrent in several other writings from the 1690s onwards. It should be noted that Leibniz's definition of parthood in the early years was still very metaphysical, even when spelled out in geometrical writings, and could not be employed for the purpose of any mathematical construction. See for instance $\$ 27$ of the Characteristica geometrica from 1679, where Leibniz himself, after having defined a part as a requisite of the whole, different from it, immediate, and in recto with other co-requisites, plainly states that these are, however, just metaphysical determinations that are of no use in mathematics. Nor did he give any mathematical ones (GM V, pp. 151-52). 
homogeneity is, on the other hand, rather complex in Leibniz's writings. The usual geometrical meaning of the term is derived from Euclid's definition of ratio and is connected with the Archimedean Axiom: two magnitudes are homogeneous if they are capable, when multiplied, of exceeding one another. ${ }^{54}$ Leibniz also proposed another, more general, meaning, saying that a thing is homogeneous to another thing if there is a third thing which is similar to the first and equal to the second. ${ }^{55}$ Similarity is here the usual geometrical notion and equality means the identity of measure. Since Leibniz seems to have the idea that any continuous transformation splits into a similarity and an equality (i.e. is composed by them), this notion of homogeneity is a very broad one and encompasses any kind of continuous (or better, bi-continuous) transformation. No triangle of any area can possibly be homogeneous with a solid sphere, because no (finite) number of such triangles, taken together, can ever amount to, or surpass, the volume of a sphere and because there is no figure, similar to the given triangle, that has the same measure (i.e. volume) as a sphere. ${ }^{56}$ In particular, a boundary is defined by Leibniz as something which is always necessarily non-homogeneous with the bounded figure (since it has a different number of dimensions), and therefore is not a part of the figure in the proper sense (even though it is in the figure). A section between two figures (e.g. the straight line in which two planes intersect) is a case of a common boundary, and it is, by definition, not a part of either figure; rather, it is in both of them.

A further, important condition of parthood that we may want to consider is that a part normally includes its own boundary. This latter condition is seldom (if ever) explicitly spelled out by Leibniz in the context of the definition of continuity but it represents an important feature of his philosophy of mathematics in general. Parts and wholes are often regarded by Leibniz as closed sets. ${ }^{57}$ The only exceptions here are infinite sets: we have

${ }^{54}$ This statement does not appear, as such, in the Elements. Rather, Euclid (or Eudoxus) states in the infamous Definition 3 of Book V (infamous inasmuch as it is very obscure, and has been the object of much speculation afterwards) that "a ratio is a sort of relation in respect of size between two homogeneous magnitudes", without however defining homogeneity. In the following Definition 4, however, Euclid states that "Magnitudes are said to have a ratio to one another which are capable, when multiplied, of exceeding one another", this latter condition being equivalent to the Archimedean Axiom. It was very easy, then, to put together the two definitions and to say that two magnitudes have a certain relation in respect of size (i.e. a ratio) to one another if they are homogeneous, that is to say, if they can be multiplied so as to exceed one another. In this way, "being homogeneous" came to mean, in some early modern texts, "being Archimedean".

${ }^{55}$ Elements VI, 25 shows how to construct a polygon which is similar to a given polygon and equal to another one. Leibniz's definition of homogeneity is, therefore, a kind of generalization of this Euclidean proposition, which however did not refer to "homogeneity" at all in the ancient tradition. In fact, the ancient tradition attributed Elements VI, 25 to Pythagoras, with a certain emphasis on the importance of the discovery of the solution of such a problem (see the famous passage in PLUT. Symp. VIII, 2, 4).

${ }^{56}$ In the Specimen geometriae luciferae, Leibniz also claimed that the Archimedean notion of homogeneity can be derived from his own more comprehensive definition, given in terms of similarity (GM VII, p. 283).

${ }^{57}$ If this were not the case, of course, the whole array of problems with contiguity would not have arisen. I have offered in DE RISI (2007, p. 194 n. 65) an example of a non-closed set (a circle without a center) employed by Leibniz in A VI, 4A, n. 178, p. 847. See BREGER (1986), who also claims that Leibniz's parts are always closed sets. We should also note that the distinction between open and closed set was quite common in the $17^{\text {th }}$ Century, and in fact it permeated not only mathematical textbooks but, to a greater degree, philosophical treatises, wherein the Scholastics commonly distinguished between internal and external limits of bodies and figures (if the limit is "external", the body in question is missing its frontier: it is topologically open). 
already mentioned, in passing, Leibniz's distinction between a syncategorematic and a categorematic infinite, and the latter implies that an infinite whole is to be considered a non-closed set. Such an infinite set should not even be a "whole" (or even a "set") in the proper sense and Leibniz, indeed, often spells out his conception of a syncategorematic infinite by saying that it does not constitute a whole. Nevertheless, from a mereological point of view, such infinite aggregates are still divisible into parts, and therefore "wholes" in a wider sense of the word. We should finally note that the mereological wholes and parts taken into consideration by Leibniz in his discussions on continuity are geometrical objects, not numerical sets. In this context, Leibniz seems to consider an object limited in its measure (a finite segment, for instance) as a finite, closed object, even though under certain considerations it might be regarded as an infinite (and therefore syncategorematic, nonclosed) aggregate of points.

It is also true, however, that a definition of parts as closed sets would trivialize under many respects the definition of continuity as completeness, for any closed subset of a complete space is itself complete. The point of Leibniz's researches in this domain, in fact, seems to be that of making explicit this last requirement. Since he clearly conceived nonclosed sets in his geometrical investigations, therefore, we will not add closure among the requirements for parthood.

Given the previous cluster of definitions, a first attempt to arrive at a new notion of continuity can be found in a short fragment which should also date from the mid-1690s. When writing it, Leibniz was clearly pleased at having discovered something quite new, as he wrote in the margins of the sheet of paper containing it:

Here I stumbled upon something memorable: The notion of a Continuum, and parts, and homogeneity, without making use of similarity, motion or transformation..$^{58}$

The definition of continuity is the following:

$\mathrm{A}$ is continuous when any two things $\mathrm{B}$ and $\mathrm{C}$ however taken, such that they exhaust [exhaurientia] A, have some thing $\mathrm{D}$ in common which exist-in [inexistens] both B and C.59

The fragment goes on to define the notion of "exhausting", specifically by differentiating it from the notion of "co-equating" or "co-integrating": the former may be a covering of the original space with some overlapping, while the latter, if it overlaps at all, does not overlap in a part:

\footnotetext{
${ }^{58}$ From the text Hic memorabilia..., to be found in LH XXXV, I, 14, Bl. 76, and published in DE RISI (2007, pp. 586-87): "Hic memorabilia nactus sum: Continui Notionem, et partis, adeoque et homogenei, non supponendo similitudinem, vel transformationem seu motum”.

59 "Continuum est $\mathrm{A}$ in quo utcunque sumta bina exhaurientia $B$ et $C$, aliquid habent commune $D$, seu utrinque tam $B$ quam $C$ inexistens", in DE RISI (2007, p. 586). In the same essay, Leibniz had already defined the notion of in-existere by saying that $B$ inexist to $A$ in the case where, if the existence of $A$ is posited, then the existence of $B$ is also immediately posited as well. See above, note 52 .
} 
Exhausting things are things, as $\mathrm{B}$ and $\mathrm{C}$, that exist-in $\mathrm{A}$ and such that nothing is in A that is not in B or C, that is to say in the composition of B and C.

(Note that it may happen that the exhausting things taken together are greater than the exhausted thing - if they have a part in common [...]).

The latter are different from co-equating or co-integrating things [coaequantia vel cointegrantia], which together are equal to the whole, while the exhausting things may be greater in magnitude than the whole even if they do not encompass anything bigger. A section is a continuum in the co-equating things which is in each of the co-equating things. [...]

If two exhausting things have nothing in common except what is necessary for continuity, what is common is called a section. ${ }^{60}$

In this convoluted passage, in which Leibniz is still looking for a good definition of several terms, continuity is defined by two parts having something in common, which may either be a part or not (since the requirement for continuity is that the parts exhaust the whole, not that they co-equate with the whole). In the last-quoted sentence, however, Leibniz insists that this common element may well be a section rather than a part, even though this is not taken, here, to be a necessary condition for continuity. As a matter of fact, this would be impossible in this context, since a few lines before the notion of "section" itself had been defined recurring to the continuum.

It is to be noted, moreover, that both exhausting and co-equating parts are coverings, in modern terms, and that a co-equating set of parts may be a partition (i.e. a covering with no common elements). A co-equating set of parts, however, may also be a covering (i.e. have some overlapping) provided that the common elements have zero measure, as is hinted at by the Leibnizian sentence on being "greater in magnitude". That is to say, the condition for having $B$ and $C$ co-equating with $A$ is that $B \cup C=A$, and either (1) $B \cap C=\varnothing$ or (2) $B \cap C \neq \emptyset$ but $m(B \cap C)=0$. Leibniz does not seem concerned with recurring to the notion of measure in defining continuity. His geometry is a metric theory, and he seems not to display any interest at the problem of giving a definition of continuity that might be applied in non-metric settings. On the contrary, the fragment goes to discuss many other issues and it is mainly concerned with an attempt to define a notion of part without recurring to homogeneity and similarity. Leibniz's preoccupation here might well be that of providing a notion of continuity that is applicable to non-spatial magnitudes, where the notion of similarity fails and this seems to him a much more important concern than the recourse to measure theory. It should also be noted that Leibniz clearly regarded it as an important logical step forward to distinguish between exhausting and co-equating parts in

\footnotetext{
60 "Exhaurientia sunt plura, ut $B$ et $C$, existentia in uno $A$, talia ut nihil sit in $A$, quod non sit in $B$ vel in $C$, seu si composito ex $B$ et $C$. (Nota. Posse fieri, ut exhaurientia simul posita sint majora eo quod exhauriunt, si scil. habeant partem commune. [...] Ab his differunt coaequantia vel cointegrantia, quae simul aequantur toti, cum exhaurientia possint toti excedere magnitudine etsi nihil amplius contineant $\dagger$. Itaque sectio est in coaequantibus continuum quod est in utroque coaequanti. [...] Si bina exhaurientia nihil habeant commune, quàm quod necesse est ad continuitatem, quod commune est dicitur sectio", in DE RISI (2007, pp. 586-87). The same train of thought is to be found in another fragment dating from the same years: "Exhaurientia ipsius $A$ sunt plura $B, C, D$ si nihil sit in A quod non sit in $B$ vel $C$ vel $D$. Vicissimque nihil in ipsis quod non sit in $A$, et tamen sit in uno, quod non est in caeteris. Continuum est $A$, in quo utcunque sumta bina exhaurientia $B$ et $C$, habent aliquid commune. ... Exhaurientia quae non habent partem communem dicuntur cointegrantia" (Euclides in definitione Diametri Circuli, unpublished in LH XXXV, XII, 2, Bl. 107).
} 
dealing with the theory of measure (as distinct, I mean, from the theory of continuity), where it is essential to partition a magnitude into a number of congruent, non-overlapping parts. ${ }^{61}$

It seems that such attempts to define parthood without similarity are given up in the following studies (at least, I am not aware of any other Leibnizian discussions on these themes). But the notion of continuity sketched here, which pleased Leibniz so much, is restated in more definite terms in the following months, this time explicitly ruling out the possibility that that intersection among parts which makes them continuous might be itself a part. This is explicitly stated prominently, if not for the first time, in the Specimen geometriae luciferae. ${ }^{62}$

Leibniz's mature definition of continuity is formulated as follows:

A continuum is a whole any two of the co-integrating [cointegrantes] parts of which (i.e. parts which, taken together, coincide with the whole) have something in common, and indeed in the case where the parts are not redundant and have no common part, i.e. when the sum of their magnitudes is equal to the total magnitude, they have at least a boundary in common. ${ }^{63}$

\footnotetext{
${ }^{61}$ This remark is, in fact, a recurrent one in Leibniz, and can be read in the Nouveaux essais, IV, VII, $₫ 10$ : "Pour ce qui est de cet axiome, que le tout est égal à toutes ses parties prises ensemble, Euclide ne s'en sert point expressément. Aussi cet axiome a-t-il besoin de limitation, car il faut ajouter que ces parties ne doivent pas avoir elles-mêmes de partie commune; car 7 et 8 sont parties de 12, mais elles composent plus que 12" (A VI, 6, n. 2, p. 414). See also a passage in a text on Mathesis generalis in LH XXXV, I, 9, Bl. 9v, which has been recently published in RABOUIN (2018, pp. 166-67).
}

${ }^{62}$ A definition of continuity similar to the one in the Specimen geometriae luciferae is to be found in a paper by Leibniz whose dating is still uncertain but which may date back to the mid-1680s. This is a draft accompanying a longer essay called Prima geometriae principia and apparently somehow related to it. Here a continuous whole is defined by using the notion of co-integrating parts, and by clarifying that the parts should have a common boundary which is not itself a part. In the lack of a complete edition of Leibniz's geometrical writings, it is hard to make any definite chronological statement about the invention of this definition. It seems safe to claim, though, that the great Specimen from the mid-1690s is the first important paper that puts this notion at the very center of the foundational discussion. In any case, the abovementioned fragment of the Prima geometriae principia reads: "Continuum est totum cujus partes duae cointegrantes habent aliquid commune, quod dicitur Terminus. ... Appello autem partes cointegrantes quae simul sunt aequales toti, et nullam habent partem communem. Terminus itaque non est pars nec est homogeneus terminatis. Alioqui foret pars" (unpublished in LH XXXV, I, 5, Bl. 5r; I thank Javier Echeverría for mentioning this text to me).

63 "Continuum est totum, cujus duae quaevis partes cointegrantes (seu quae simul sumtae toti coincidunt) habent aliquid commune, et quidem si non sint redundantes seu nullam partem communem habeant, sive si aggregatum magnitudinis eorum aggregatio totius aequale est, tunc saltem habent communem aliquem terminum" (GM VII, p. 284). We may note that in the Specimen Leibniz did not define the term "cointegrans", which had been defined in the other (probably contemporary) fragment which we have just examined. Had the notion been defined in identical manner in the two texts, the Leibnizian addition in the Specimen "and such indeed that..." would have been pleonastic, since co-integrating parts have, by definition, no part in common. Since, however, Leibniz had not defined the notion, he possibly felt the need for this further specification. In the case, however, that "cointegrans" here should signify no more than just "exhausting" (i.e. a covering allowing parts in common), we may note that the clause introduced by "and such indeed that..." is actually a second condition for the definition. It is not introduced as a disjunction (two parts should have a part in common or at least a boundary), but as a further requirement. The latter interpretation is confirmed by an incidental passage in the Specimen in which Leibniz mentions a continuous space the parts of which cannot have any part in common (GM VII, p. 266). 
Here the final and most important condition - i.e. that the common element should be a section and not a part - is finally in place. Leibniz is very clear that such a definition must apply to a wider range of objects than just the geometrical magnitudes, and in fact he himself quickly moves on to discuss continuous transformations and fibrations, as we have seen above (the example of the family of ellipses). The reference to the measure of the parts is, however, still present. It is to be noted, moreover, that in this definition (and the following one) Leibniz refers to "wholes" which have parts. It is not immediately clear whether these must have a boundary or not, or be limited or not.

It seems that Leibniz repeated such a definition several more times starting from these years onward. ${ }^{64}$ The last and possibly most perfected occurrence of it is probably to be found in the mature Leibnizian masterpiece on geometry, the In Euclidis $\pi \rho \tilde{\omega} \tau \alpha$ from 1712. This treatise summarizes three decades of Leibniz's work on the foundations of geometry in the form of a detailed commentary on the definitions and the axioms of the Elements. In it Leibniz offers a variation on his classical definition of a section, which recurs to the previous notions of co-integrating:

The section of a magnitude is anything which is common to two parts of the magnitude which have no part in common. Let $\mathrm{AB}$ be a magnitude and its parts be $\mathrm{AD}$ and $\mathrm{BC}$, which have the straight line $\mathrm{CD}$ in common. The latter is in $\mathrm{AD}$ and is in $\mathrm{BC}$, even though these parts have no part in common. In fact, $\mathrm{CD}$ is not a part of $\mathrm{AD}$, nor a part of $\mathrm{BC}$. The evidence is that $\mathrm{AD}$ $+\mathrm{BC}+\mathrm{CD}$ is not greater than $\mathrm{AD}+\mathrm{BC}$, that is to say, the former does not have to the latter any ratio of the

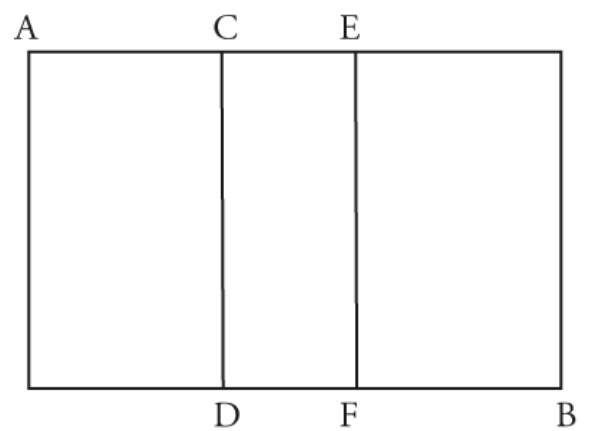
greater to the lesser, since $\mathrm{AD}$ and $\mathrm{BC}$ are parts equating the whole. On the other hand, if the parts should have a common part, as for instance the parts $\mathrm{AF}$ and $\mathrm{BC}$ of the whole $\mathrm{AB}$ have the common part $\mathrm{CF}$, then $\mathrm{AF}+\mathrm{CB}$ would be greater than $\mathrm{AB}[\ldots]$, and nonetheless $\mathrm{AF} \oplus \mathrm{CB}$, that is to say $\mathrm{AF}$ and $\mathrm{CD}$ taken together, are not greater than $\mathrm{AB}$. It is important to mark this difference between the addition of quantities, and the taking-together [simul-sumtionem] of things. As the mental addition of quantities [quantitatum] is designated by + , so the real addition of magnitudes [magnitudinum], or of their quanta [quantorum], is designated by $\oplus .^{.5}$

\footnotetext{
${ }^{64}$ Among the unpublished papers from the 1690s, see for instance the short essay in LH XXXV, VII, $30, \mathrm{~B} 1$. 128, stating: "Continuum est, cuius duae partes cointegrantes habent commune quod dicitur terminus. Partes cointegrantes voco quae simul sunt aequales toti, nec habent partem communem...”.

65 "Sectio magnitudinis est quidquid est commune duabus Magnitudinis partibus partem communem non habentibus. Esto Magnitudo $\mathrm{AB}$, ejusque partes $\mathrm{AD}, \mathrm{BC}$, quibus communis recta $\mathrm{CD}$, quae est et in $\mathrm{AD}$ et in $\mathrm{BC}$, etsi hae partes non habent partem communem. Nam CD non est pars ipsius AD nec ipsius BC. Hujus indicium est, quod $A D+B C+C D$ non est majus quam $A D+B C$, seu non habet ad ipsum rationem majoris ad minus, cum $\mathrm{AD}$ et $\mathrm{BC}$ sint partes aequantes totum. Sed si partes partem communem haberent, uti ex. gr. $\mathrm{AF}$ et $\mathrm{BC}$ partes ipsius $\mathrm{AB}$ habent partem eommunem $\mathrm{CF}$, tunc $\mathrm{AF}+\mathrm{CB}$ majus foret quam $\mathrm{AB}$ (cum sint partes complentes quidem totum $\mathrm{AB}$, ut faciunt $\mathrm{AD}$ et $\mathrm{BC}$, sed non aequantes, ut etiam faciunt $\mathrm{AD}$ et $\mathrm{BC}$ ), et tamen $\mathrm{AF} \bigoplus \mathrm{CB}$ seu $\mathrm{AF}$ et $\mathrm{CB}$ simul sumta, non sunt plus quam $\mathrm{AB}$. Quod discrimen inter additionem quantitatum, et simul-sumtionem rerum probe notandum est. Et ut additio mentalis quantitatum designatur
} 
Needless to say, the discussion of the notion of a section is functional to the definition of continuity, which is still defined by a mereological structure such that the whole is decomposed into parts which have no part, but rather a section, in common:

In order for quantity to be continuous, two requirements must be fulfilled: first, any two parts which, taken together, equal the whole must have something in common which, however, is not itself a part; second, the parts must be, as is commonly said, exterior to one another, that is, it must be possible to take any two parts (which together do not equal the whole) which have nothing in common, not even a minimum. ${ }^{66}$

The last requirement of the second definition is the partes extra partes clause, which was not included in the previous definitions, since in the essay which we are discussing now Leibniz is concerned only with geometry (Euclidean geometry, in fact), and gives a more restricted definition of continuity which applies only to geometrical magnitudes. ${ }^{67} \mathrm{He}$ also explicitly wanted to exclude angles from the definition of continuous things, since he denied that angles are magnitudes, that is to say parts of the plane (stating rather that they are relations between lines).$^{68}$ On the other hand, in the In Euclidis $\pi \rho \tilde{\omega} \tau \alpha$ we have the advantage that any reference to measure has disappeared, and the definition is given in purely mereological and situational terms. In this respect, it is much neater and more mathematically worthy than the preceding one, even though the reference to parthood needed here still requires the notion of homogeneity, and this latter requires, in turn, the notions of similarity and equality (i.e. identity of measure) so that the definitional advantage might be not so great. ${ }^{69}$

Despite these differences, however, and despite the fact that Leibniz's formulations remain a bit vague as regards their exact meaning (as they stand they may be formalized in many different ways), Leibniz's actual use of them in geometrical demonstrations makes

per + , ita additionem realem magnitudinum, seu ipsorum quantorum designo per $\oplus$, donec aliquid commodius occurrat." (GM V, p. 184).

66 "Porro ad continuum duo requiruntur, unum ut duae quaevis ejus partes totum aequantes habeant aliquid commune, quod adeo pars non est; alterum ut in continuo sint partes extra partes, ut vulgo loquuntur, id est ut duae ejus partes assumi possint (sed non aequantes), quibus nihil insit commune, ne minimum quidem" (GM V, p. 184).

${ }^{67}$ This seems to be, however, a consequence of the definition: for in intensive quantities (such as forces) two parts always overlap in a further part (i.e., the smaller of the two), and therefore they would never be said to be continuous. In this sense, the partes extra partes clause may have also been seen by Leibniz as an opening toward a different definition of continuity that was to apply to intensive quantities — since he surely wanted to declare forces or speed to be continuous, and his mereological definition did not allow this.

${ }^{68}$ This is explicitly stated after the definition in the In Euclidis $\pi \rho \tilde{\omega} \tau \alpha$. Two angles of different width would coincide in a common part (i.e. the entire smaller angle) and therefore should not be considered to be continuous, and much less a magnitude: "Magnitudo est continuum, quod habet situm. Angulus autem continuum non est" (GM V, p. 184).

${ }^{69}$ Note also that in general Leibniz still defines quantity in the classical way as something that has parts. In this sense, he had probably not seen that a purely mereological definition was more general than a definition recurring to measure. Moreover, the definition of section hinted at above still refers to the comparison on quantities. 
quite clear that the last definitions (the ones in the Specimen and in the In Euclidis $\pi \rho \tilde{\omega} \tau \alpha$, along with other fragments in between the two) all amount to the same idea: a geometrical whole is continuous if, and only if, any two arbitrarily-chosen parts of it are such that if the two parts together cover the whole and have no common part, they still must have something else in common, namely, their boundary. We may attempt a modern, symbolic expression of the Leibnizian definition of continuity in order to better clarify some of the most important aspects of it. Let be $X$ a geometrical magnitude; $\mathcal{P}(X)$ the collection of its parts, where a part is in the Leibnizian sense a proper subset of the whole, homogeneous to it; and call $\partial p$ the boundary of a part $p$ (irrespective of the fact that such a part contains or not its own boundary-whether it is a closed set or not). ${ }^{70}$ Then we may say that

$$
X \text { is continuous iff } \forall p_{1} p_{2} \in \mathcal{P}(X),\left(p_{1} \cup p_{2}=X\right) \rightarrow\left(\left(p_{1} \cap p_{2} \notin \mathcal{P}(X)\right) \rightarrow\left(\exists b \subset X: b=\partial p_{1}=\partial p_{2}\right)\right)
$$

It is easy to understand Leibniz's intent with this definition if we apply it to a segment and its intervals (taken as its parts). In fact, where we give a numerical representation of such a segment, it even becomes apparent that Leibniz's definition of continuity approaches Dedekind's notion of completeness given by the idea of a cut. If we take, for instance, the interval of rational numbers between 0 and 2 (which is dense, but not complete), we are not able to partition it as Leibniz's definition of continuity requires. If we consider, for example, the cut at number $\sqrt{ } 2$, which is between 0 and 2 but irrational, we can easily see that we may either find a partition of the interval in two sets that have no element in common, for their common boundary does not exist in the set (e.g. the sets of rational numbers strictly greater than $\sqrt{ } 2$, and all rational numbers strictly lesser than $\sqrt{ } 2$ ), or a covering of the interval in two parts which have an entire part in common (e.g. all rational numbers equal or greater than a certain $a<\sqrt{2}$, and all rational numbers equal or less than a certain rational number $b>\sqrt{ } 2$; the common part of which is the set of rational 0 numbers between $a$ and $b$ ). In either

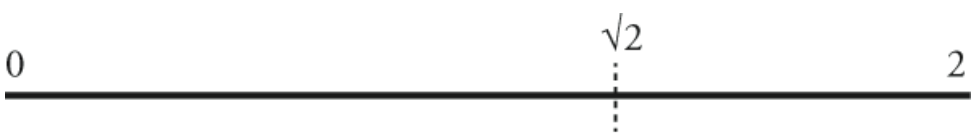
0 case, the whole would not be continuous according to Leibniz's 0 definition: the first choice has an empty intersection; the second choice forces the sets to have a common part, rather than a boundary. It is only the existence of $\sqrt{ } 2$ itself that may allow us to divide the interval into the two closed sets of numbers $[0, \sqrt{2}]$ and $[\sqrt{2}, 2]$, the only common element of which is $\sqrt{2}$, which is not a part (but a section) of the intervals. The same reasoning may be repeated for all irrational numbers in the interval, and therefore the only complete interval is that

\footnotetext{
${ }^{70}$ That is to say, $\mathcal{P}(X)$ is a subset of the standard, set-theoretical Poweset of $X$. I have chosen this formulation of the Leibnizian definition, relying on the explicit reference to boundaries that we find in the Specimen (while it seems impossible to characterize the boundary simply stating $b \notin \mathcal{P}(X)$ ). I have also stressed the existence of such a boundary, in order to better show the similarity with Dedekind's definition. It seems clear to me, from Leibniz's examples, that he had in mind some sort of existential statement. I may add that the formula applies differently to topological spaces and subspaces (for boundaries may be differently considered in the two cases), even though this difference is far beyond Leibniz's "seminal" topological awareness.
} 
composed by all the real numbers between 1 and 2. It is continuous according to Leibniz's definition. ${ }^{71}$

With such a definition, therefore, Leibniz was able to give an exact mathematical notion of continuity which approximates to our modern definition of completeness and might be employed as the foundation of continuity in geometry. There are some striking similarity with Dedekind's own definition, which also cuts the set in two parts, and asks for the existence of a separating individual; such a role is here played by the boundary of the parts, which has to be in common between them. We must be careful, of course, about attributing to Leibniz a fully-fledged definition of completeness or making him a forerunner of Dedekind. There is no doubt that the gap between the two formulations of completeness is enormous and that Leibniz's still sloppy definition, which does not apply without adjustments to its intended object, still falls short of that definitional exactitude that is Dedekind's greatest merit.

Of course, the main difference between Leibniz's and Dedekind's approaches is to be found in Dedekind's vigorous rejection of a geometrical foundation for completeness and his insistence that this notion should be grounded rather on a consideration of numbers. This is an important $19^{\text {th }}$-Century view to which nothing could have exactly corresponded in the thought of Leibniz or his contemporaries. In the $17^{\text {th }}$ Century, most mathematicians still endorsed the Greek view (clearly expounded by Aristotle) that numbers are discrete quantities - that is to say that numbers are just natural numbers $(\mathbb{N})$. The status of real numbers was still very much ambiguous in the early modern age, and the general view was that irrational magnitudes such as $\sqrt{ } 2$ were to be considered primarily geometrical objects. Irrational numbers might, indeed, be employed in order to do calculations involving such geometrical magnitudes and some kind of correspondence between real numbers and the points of a line was surely envisaged (as it is obviously necessary in the foundations of Cartesian geometry). Nevertheless, irrational numbers were still regarded as an image of the continuum (in Wallis's words), or a sign of magnitude (in Barrows's words), rather than as anything forming a continuous whole in itself. This being the case, the set of all real numbers was not generally considered to be a proper mathematical object (but just a set of tools), and $\mathbb{R}$ was not investigated in any structural way. In this context, it remained doubtful whether real numbers should be taken to be continuous in any proper sense. But even if they may have been considered so from time to time, there is no doubt that their continuity was parasitic on the continuity of geometrical magnitudes rather than primary or original: while Dedekind's theory claimed the opposite. In this connection, we may note that Leibniz went further than his contemporaries in disentangling the consideration of numbers from that of geometrical magnitudes, and he always insisted on some ontological and epistemological independence of the former from the latter. Numbers are for him essentially relations and in this respect they have some ideal subsistence independent of space or extension. A natural number is sometimes defined by Leibniz (following Euclid) as a collection of unities. A number in general (including rational and irrational numbers) is also defined by him as anything which is homogeneous to a unity, where homogeneity seems

\footnotetext{
${ }^{71}$ See DE RISI (2007, pp. 196-98), where I had offered a slightly different modern reformulation of Leibniz's definition. The fairly intuitive example given above, of course, may be complicated a bit if we mean the rationals as a subspace of the reals (rather than a topological space in its own right). In this case, the boundary of the rationals are the reals themselves, and the two parts also have boundaries in 0 and 2 .
} 
to be taken in the sense of the Archimedean Axiom. ${ }^{72}$ On the other hand, he always denied that infinite collections of numbers may be true wholes (they are rather syncategorematic aggregates), and in this respect he, like his contemporaries, never seems to consider or investigate $\mathbb{N}, \mathbb{Q}$, or $\mathbb{R}$ and their properties (including their continuity, or lack thereof). ${ }^{73}$ In any case, as far as I know Leibniz never attempted to apply his definition of continuity to real numbers.

We have also noted that there is a certain ambiguity in Leibniz's writings on the necessity that a whole should always have its boundaries. In fact, Leibniz seemed concerned solely, in his foundational studies on continuity, with excluding "gaps" from the continuum and he did not explicitly discuss the case of missing boundaries. It is possible that he had considered the open real interval $(0,1)$, which is Dedekind-incomplete, to be a continuous whole after all.

Speaking more generally, it does not seem that mereology (or topology) is the right setting in which to express Dedekind's notion of completeness. It is true, however, that Leibniz's mereological structure is enriched by a more robust definition of parthood (namely, one in terms of homogeneity and closure) which adds a further structure that, aptly interpreted, might be able to capture some more aspects of completeness. ${ }^{74}$ It is still remarkable that Leibniz's definition of continuity employs an explicit quantification on the set of parts (which was not a feature of the ancient definitions of continuity). This clearly hints in the direction of a "second order property" as far as completeness is concerned. In this respect, his ability to distinguish from one another completeness and density (a first order property, which does not call into play the set of all parts) should definitely be considered a logical breakthrough.

The modern notion of completeness is, however, still insufficient to exhaust all that Leibniz meant when he evoked the notion of continuity. Since, in fact, Leibniz's definition is just a refinement of the old Aristotelian notion, it also inherits the mathematical merits of this latter. In particular, it seems apt to capture the topological notion of connectedness. We have already seen that connectedness, which is a much simpler property than completeness, could perhaps already have been hinted at in the Aristotelian definition. ${ }^{75}$ But whereas reading a clear mathematical intent into Aristotle's quite physical definition requires a certain stretch, Leibniz's purely mathematical treatment of the notion seems indeed to provide a viable definition of connectedness. In particular, since connectedness may be defined as the impossibility of representing the whole as the union of disjoint closed sets, Leibniz's explicit statement that parts must have boundaries (a statement that is not to be found in Aristotle), together with the possibility of conceiving of the set of all possible parts of a whole (likewise lacking in Aristotle), seems to constitute a real step forward

\footnotetext{
${ }^{72}$ Note that the definition through homogeneity seems not be able to entirely replace the more restricted one in terms of natural numbers as aggregates of unities, since the Archimedean property seems to require natural numbers to be formulated. On Leibniz's notion of numbers, see the recent paper by SEREDA (2015).

${ }^{73}$ We may note that Leibniz attributed parts and homogeneity to each single number (which is in some respect an aggregate, or a set), not to the set of numbers. He might have stated that 7 is homogeneous with $\sqrt{2}$, but he did not claim that the set of numbers $[0,1]$ is a homogeneous part of $\mathbb{R}$.

${ }^{74}$ The notion of boundary and closure may be defined, in fact, in a purely mereological setting. The question of homogeneity is more complicated, as Leibniz's definition of it remained a bit uncertain.

75 See above, note 20 .
} 
toward an exact definition of connectedness. A set of real numbers such as $[0,1] \cup[2,3]$, which is Dedekind-complete but disconnected, would therefore count for Leibniz as a discontinuous set. The same is true for those topologically discrete sets, such as $\mathbb{Z}$, which are disconnected but complete: they would be discontinuous according to Leibniz's definition. It should be remarked that the flexibility of Leibniz's notion of continuity, which encompasses both completeness and connectedness, is rather artificial and is probably grounded on some ambiguity in the formulation of the principle. ${ }^{76}$ There is no doubt, however, that such was Leibniz's intent and that, therefore, Leibniz's concept of continuity should be considered to be a hybrid topological/mereological notion combining completeness and connectedness.

We may also note that Leibniz's definition of continuity does not seem to entail density. In principle, it seems be possible to start (for example) with extended elements endowed with a boundary and homogeneous with the whole (i.e. atomic parts) and to make a continuous whole out of these latter by connecting them in their boundaries. Leibniz, however, does not seem to ever seriously consider this possibility, since, of course, he believes that he possesses important (and classical) arguments in favor of the infinite divisibility of geometrical extension. All geometrical applications of Leibniz's definition of continuity, therefore, assume density, and thus an atomless mereology. The parts involved in the definition of continuity are infinite sets of points and these are always further divisible. Nevertheless, the points themselves, as we have seen, are not parts of the whole, so that a point is not a mereological atom.

Something similar may be said about the Archimedean Axiom. Even though it may be employed in defining what a part is (since it may be involved in the notion of homogeneity), nothing seems to exclude the possibility that, in a continuous whole, there might also be non-Archimedean elements (which would not themselves be parts of it, of course).

It may not be surprising that the inventor of the Calculus felt the need to explore the deepest questions regarding continuity and there is no doubt that a similar definition would have been almost impossible prior to the development of infinitesimal analysis, along with the subtle discussions on density, closure, or homogeneity that it engendered. Nonetheless, Leibniz was able to achieve a degree of clarity in this definition that was to remain lacking in the work of most mathematicians active in the centuries between him and Dedekind.

\section{\$6. A gapless proof of Elements I, 1}

Leibniz's notion of continuity was first conceived of and developed for elementary geometry and it was here that it found its first and foremost applications. In fact, a new

\footnotetext{
${ }^{76}$ Connectedness may be defined as the impossibility of representing the whole topological space as the disjoint union of two closed sets. The above-sketched "Leibnizian" formula recovers connectedness by asking that in a connected space any partition in two (also non-closed) sets must have some element in common when we consider their boundaries (i.e. their closure). Alternatively, one could define parts as closed sets, and then define continuity simply as following: $X$ is continuous iff $\forall p_{1} p_{2} \in \mathcal{P}(X),\left(p_{1} \cup p_{2}=X\right) \rightarrow\left(p_{1} \cap p_{2} \neq \varnothing\right)$, which is good rendering of Leibniz's statement if we forget the (quite complex) "which is not a part" clause. This may approach a bit more the simpler Aristotelian setting.
} 
demonstration of Elements I, 1, is attempted in the Specimen geometriae luciferae in the lines immediately following the discussion of continuity. This is also an important innovation, since Leibniz's previous approaches to this Euclidean proposition seemed simply to assume the possibility of giving a mathematically viable definition of continuity, without ever attempting to do so.

Leibniz's first encounter with the foundational issues in Elements I, 1 may well have been in 1679, when he first attempted a characteristica geometrica and began to seriously work at his project on analysis situs. At the time, he immediately detected the gap in the Eucliedean proof, and complained that Clavius had not noticed it. ${ }^{77}$

We have a short essay entirely dedicated to this problem dating from those years, which begins by stating that:

Euclid wanted to keep the greatest rigor in demonstrations: to this effect, he even proves that two sides of a triangle taken together are greater than the third, something that was mocked by the Epicureans, saying that this is known even by an ass. Nonetheless he did not prove other things that seem to need much more proof: and for instance in Elements I, 1, where he teaches how to construct an equilateral triangle on a given basis, he assumes that two circles drawn from the endpoints of the straight line (taken as the base) and with radius equal to the straight line, cut each other. This is not evident at all. ${ }^{78}$

Yet, in the following discussion of the matter, Leibniz says that in order to prove that the two circles meet, one has to rigorously prove:

1) That the circumference of each circle is partly inside and partly outside the other circle (for if this is established, the circumference would necessarily intersect the other circumference, given the definition of section).

\footnotetext{
${ }^{77}$ See Leibniz's letter to Vagetius, from December $12^{\text {th }}, 1679$, stating that "Clavius cum primam primi logice resolvere vellet, nihil egit; neque enim animadvertit vel ipse vel alius interpres demonstrationem Euclidis indigere hac propositione, quod duo circuli illic descripti alicubi sese secent. Quod aut probandum aut saltem assumendum erat inter principia” (A II, 1, n. 218, p. 768). A similar statement recurred still in the Recommandation pour instituer la science generale from 1686: "A quoy je trouve qu'Euclide, tout exact qu'il est, a manqué quelques fois, et quoyque Clavius y ait souvent suppléé par sa diligence, il y a des endroits, où il n’y a pas pris garde, dont un des plus remarquables et des moins remarqués se rencontre d'abord dans la demonstration de la premiere proposition du premier livre, où il suppose tacitement que les deux cercles qui servent à la construction d'un triangle equilatère, se doivent rencontrer quelque part, quoyqu'on sçache que quelques cercles ne se sçauroient jamais rencontrer" (A VI, 4A, n. 161, p. 705). In a passage of his Demonstrationes Euclideas Leibniz complained that even Clavius's reduction of Euclid into syllogisms did not elicited in him a doubt about the existence of the intersection point: "Hoc demonstrare quod circuli se secent Euclides et interpretes neglixere, etiam cum in Syllogismos redegere demonstrationem" (still unpublished in LH XXXV, I, 3, Bl. 2r).

${ }^{78}$ This and the following quotations are from an unpublished paper in LH XXXV, I, 2, Bl. 6-7, which has been transcribed in Echeverría's doctoral dissertation: see ECHEVERRÍA (1980, vol. 2, pp. 43-51). The original latin reads: "Euclides summum rigorum observare voluit in demonstrando: ideo probat quod in triangulo duo latera sint tertio majora, quod, ut Epicurei ridentes ajebant, etiam asinus novit. Interea non probat alia quae magis probatione indigere videntur exempli causa in prop. 1 lib.1 ubi triangulum aequilaterum super data basi constituere docet, assumit duos circulos ex rectae (quae pro basi sumitur) extremis et intervallo ipsius rectae descriptos, sese secare. Quod non equidem ita manifestum est”.
} 
2) That the radius of the circle, extended, will intersect the circumference in two points only. ${ }^{79}$

Leibniz deals with the topic at length and his considerations are rich in reflections about order and the reciprocal positions of points. Basically, he attempts to employ mereological considerations in order to recover principles of order (by exploiting, as we would say today, the intrinsic partial ordering of any mereological structure). In fact, in the same group of essays (though not in this one) he was to arrive at a very neat formulation of Pasch's axiom, which is the most important principle ruling the ordering of points in the plane. ${ }^{80}$ But however interesting these considerations may be for the birth of a geometry of space and situational (and ordering) relations, it is remarkable that in this early essay Leibniz never attempted to give any further explanation of the existence of the meeting points. The parenthetical remark about continuity in the above-mentioned quotation seems to be the only thing he has to say: by the definition of "section" (which he never gave), one should be able directly to show that the circles actually do intersect. This is restated at the end of the essay, the last words of which are:

.... and therefore the circumference is partly inside and partly outside the other circle, and thus it intersects its boundary and thus meets it. ${ }^{81}$

In a related essay, Leibniz attempted to further belabor the point, and moved decidedly towards some "topological" consideration of the intersection, by stating that if a point is inside (resp. outside) a given figure, that an entire part (say, a neighborhood) is inside (resp. outside) the figure. He then attempted to prove the existence of the point of intersection, by speculating on the fact that two parts of a continuous figure, which has a point inside and a point outside another closed figure, must meet the latter's boundary. Such texts are really remarkable from a proto-topological point of view, but in 1679 Leibniz still lacked a

\footnotetext{
79 "Primum: Circumferentia in unius (DB) esse partim in altero partim extra alterum, EA (hoc enim posito illa hujus ambitum secet necesse est per sectionis definitionem). Deinde: Radium productum secare circumferentiam in duobus tantum punctis" (ibid.).

${ }^{80}$ The essay is unpublished in LH XXXV, I, 2, Bl. 14r; transcribed in ECHEVERRíA (1980, vol. 2, pp. 78-79). I may mention that Pasch's Axiom, as it appears also in Hilbert's Grundlagen (as Axiom II, 4), may be taken as a Line-Line intersection principle, as it states that two segments (a side of a triangle and a straight line) meet in a point. As it should be conceived as an order axiom, though, it may be reformulated in such a way not to imply the existence of the point of intersection, but just the reciprocal position of the lines: and such a modified axiom would not change the underlying model of Hilbert's Grundlagen. In other words, the "continuity" part of Pasch's Axiom is redundant and, given a weaker form of Pasch's Axiom (i.e. a statement that does not require an actual intersection), it could be derived from the remaining Hilbert's axioms. I thank Victor Pambuccian for an enlightening discussion on this topic.

81 "Est ergo circumferentia BD partim in circulo ABE partim extra, adeoque ejus ambitum secat seu ac proinde ei occurrit" (ibid.). The same line of reasoning was held by Leibniz in another essay dating from the same 1679, in which he attempted to give a further "situational" argument of the fact that the circle on the right has a point inside and a point outside the circle on the left: "ergo peripheria dextra sinistra occurrit" (LH XXXV, I, 11, Bl. 55, also published in ECHEVERRÍA (1980, vol. 2, pp. 295-301). A similar statement is still repeated in Leibniz's Demonstrationes Euclideae from the early 1690s, still unpublished in LH XXXV, I, 3, Bl. 3.
} 
definition of continuity such as that of the Specimen, and the proof does not seem to conclude. $^{82}$

A few years later, Leibniz sketched a very similar proof, that he enriched with a demonstration that the point of intersection of the two circles does not fall on the given segment (the base of the equlateral triangle), and that the points of intersection among circles cannot be more than two (Elements III, 10). He still concluded appealing to the general principle that

If a continuum has a part inside and a part outside a figure, it intersects the boundary of such figure. ${ }^{83}$

In the same years, Leibniz continued to work at the demonstration of Elements I, 1, and attempted to reshape it into a semi-formal demonstration in his important essay Specimen analyseos figuratae. The remarkable breakthough of this essay seems to be Leibniz's clear awareness of the necessity of an existential statement (such as the existence of the boundary, in his mature definition of continuity) in order to prove the theorem. As a matter of fact, Leibniz offered a formal derivation that the two circles cross one another, which is not very different from those already elaborated in 1679, which we have mentioned above. Then, however, rather than embarking in providing a definition of continuity, and without even mentioning the continuity of the circles, he introduced a postulate stating that if two things cross, their point of crossing (i.e. the intersection) exists. From an epistemological point of view, recurring to a postulate could not solve the issue for Leibniz (who wanted to derive the entire mathematics from definitions), and yet this formal essay of the 1680s can be seen as an important step forward in the uderstanding of the difference between a merely situational property (the crossing) and a further existential statement (the intersection), which cannot be given by situation alone. ${ }^{84}$

In the same months, apparently, Leibniz penned down a further fragment of proof of Elements I, 1, which seems to cash out most of the work done up to this point, and which grounds the existence of the point of intersection on a continuity axiom (axioma de continuis), which is spelled out in terms that are not very far away from the final definition of continuity in the Specimen geometriae luciferae, but still seems to lack full generality. ${ }^{85}$

Ten years later, when Leibniz was able to actually give a mathematically viable definition of continuity, the discussion of Elements I, 1 that he engages in is still somehow similar and still based on a proof that some points of a circle are inside and some outside of the other circle. But at this point, in the Specimen geometriae luciferae, Leibniz is able to call

\footnotetext{
${ }^{82}$ The most remarkable text in this respect has been published in ECHEVERRÍA, PARMENTIER (1995, pp. 26670).

${ }^{83}$ This can be read in an unpublished fragment in LH XXXV, XII, 1, Bl. 67r: “...sequitur ex hac generali propostione: Si continuum partem habet intra figuram partem extra, occurrit circumferentiae ejus aliquo puncto".

${ }^{84}$ The Specimen analyseos figuratae is a very remarkable essay still unpublished in LH XXXV, I, 14, Bl. 21-22. The postulate sounds: "Postul. 2: Datis occurrentibus habetur occursus". I thank Javier Echeverría for providing me with a transcription of this text.

${ }^{85}$ The latter fragment is still unpublished in LH XXXV, XII, 1, Bl. 69r. The dating of such fragments is still uncertain.
} 
upon his new definition of continuity and to prove, rather than assume, the existence of the intersection point (assuming, of course, the continuity of the two circumferences). Because, if the point of intersection were missing, there would not be a decomposition in parts of a circumference that would exhaust the whole circumference and yet intersect the first part at a boundary (a point) only. This is basically a derivation of the Circle-Circle intersection axiom. ${ }^{86}$

The In Euclidis $\pi \rho \tilde{\omega} \tau \alpha$, on the other hand, applies in a rather abridged way the notion of continuity to prove that the diameter of the circle does cut the circumference itself, thus fulfilling the second requirement of Leibniz's early discussion of Elements I, 1:

Moreover, it follows from the nature of continuity that every continuum which is partly inside and partly outside a figure falls on its boundary. In fact, any two parts of a continuum that together make the whole have something in common even though they have no part in common. Let there be, then, two parts of a straight line, one inside and the other outside the circle. They have a common point. This point is also common to the circle, for it is in the part of the plane falling inside the circle and also in the part of the plane in which the straight line falling outside the circle lies. But anything that is common to the two parts of the plane, is in their common section, that is, the circumference. ${ }^{87}$

A few lines below, a symbolic proof employing the machinery of the characteristica situs is also performed. In the following passage, $\underline{\mathrm{X}}$ means, as before, the collection of all X's:

It is worth arranging this demonstration in terms of the Calculus of Situation, so that we can familiarize ourselves a little with this latter. A plane is divided by the circumference of a circle into two parts, $\underline{X}$ and $\underline{Y}$, the first $\underline{X}$ being inside the circle and the second $\underline{Y}$ outside it. The circumference will, therefore, be $\underline{X}$ and $Y$, that is to say, the locus of all points in common that are both $\mathrm{X}$ and $\mathrm{Y}$. Let the straight line be extended from a point $\underline{Z}$, then the part of it which is inside the circle will be $\underline{Z}$ and $X$, while the part outside of it will be $\underline{Z}$ and $Y$. Their common point then (following the nature of continuity) is $\mathrm{Z}$ and $\mathrm{X}$ and $\mathrm{Y}$; thus, it is $\mathrm{X}$ and $\mathrm{Y}$; therefore, it is in $\mathrm{X}$ and $\mathrm{Y}$, that is to say, in the circumference. ${ }^{88}$

\footnotetext{
${ }^{86}$ The new proof of Elements I, 1, is to be found in GM VII, p. 284.

87 "Porro sequitur ex natura continuitatis omne continuum, quod est partim intra partim extra figuram, cadere in ejus terminum. Nam continui duae partes quaevis totum aequantes habent aliquid commune, etsi partem communem non habeant. Sint ergo duae partes rectae, una intra circulum, altera extra circulum. Hae habent punctum commune. Id punctum etiam commune est tum circulo, quia est in parte intra circulum cadente, tum parti plani rectam continentis extra circulum jacenti, quia est in parte extra circulum jacente. Quicquid autem duabus plani hujus partibus est commune, id in communi earum sectione est, nempe in Peripheria" (GM V, p. 196).

${ }^{88}$ Here is the original passage, with some corrections made to Gerhardt's transcription: "Operae autem pretium erit, hanc demonstrationem Calculo situs nonnihil accomodare, ut ei paulatim assuescamus. Planum per peripheriam circuli dividitur in duas partes $\underline{X}$ et $\underline{Y}$, unam $\underline{X}$ [intra] circulum, alteram $\underline{Y}$ [extra] circulum. Peripheria autem erit $\underline{X \text { et } Y}$ seu locus omnium punctorum, quae simul sunt $X$ et $Y$. Recta autem ab uno termino producta sit $\underline{Z}$, ejus una pars, quae intra, circulum, est $\underline{Z}$ et $X$, quae extra circulum, est $\underline{Z}$ et $Y$. Punctum ergo utrique commune (ob naturam continuitatis) est $Z$ et $X$ et $Y$; ergo est $X$ et $Y$; ergo est in $\underline{X \text { et } Y}$ seu in peripheria” (GM V, p. 197).
} 
This must count, of course, as a symbolic proof of the Line-Circle intersection axiom. In both cases Leibniz was able to recover the ad hoc continuity principles which had been introduced by previous mathematicians in order to perfect Euclid's proofs using his new notion of continuity as completeness. He was able, in fact, to demonstrate these axioms as special cases of his more powerful principle and in the Specimen he explicitly generalized this latter so as to make it apply to all lines and surfaces:

And in general, if any continuous line whatsoever is in any surface whatsoever, and it is partly inside and partly outside of a part of said surface, it will somewhere intersect the boundary of this part. And if any continuous surface whatsoever is partly inside and partly outside of any solid whatsoever, it will necessarily intersect somewhere the boundary of said solid. ${ }^{89}$

On the following page of the Specimen, Leibniz generalized his results even further by producing a symbolic expression for sets with common parts and common sections which easily extends the notion of continuity to any possible class of situational elements. It is an implementation of Leibniz's characteristica geometrica deploying a proper notion of continuity rather than special axioms for the intersections of lines and circles:

We may express this also with a kind of calculus. Let's call $\underline{Y}$ a part of extension, and let us use the general name $\mathrm{Y}$ to refer to whatsoever point falls within this part $\mathrm{Y}$. Let us call all points of this extension that fall outside of this part by the general name $\mathrm{Z}$, and call $\mathrm{Z}$ the whole extension outside of the part $\underline{Y}$. It is clear that the points falling within the boundary of the part $\underline{Y}$ are common to $\underline{Y}$ and $\underline{Z}$, and that they may partly be called either $Y$ or $Z$, that is to say, that some $\mathrm{Y}$ is $\mathrm{Z}$, and some $Z$ is $Y$. The whole extension, on the other hand, is composed by $\underline{Y}$ and $\underline{Z}$ together, and it

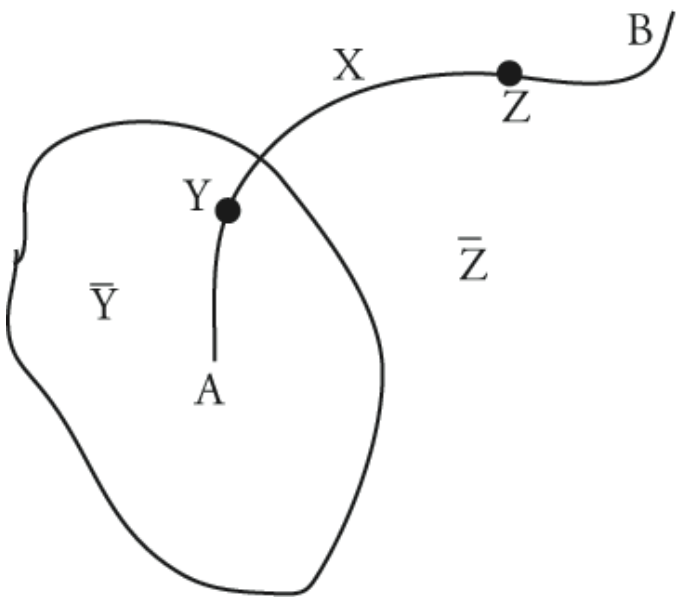
is $\underline{Y} \oplus \underline{Z}$. All its points are either $Y$ or $Z$, and some of them are both $Y$ and $Z$. Assume now that a new extension is given, namely AXB, which exists in the previous extension $\underline{Y} \oplus \underline{Z}$, and let us call this new extension by the general name $\underline{X}$, so that all its points, regardless of which, is $X$. It is immediately clear that every $\mathrm{X}$ is either $\mathrm{Y}$ or $\mathrm{Z}$. If it is established from our data that some $\mathrm{X}$ is $\mathrm{Y}$ (e.g. A, which falls within $Y$ ) and also that some $X$ is $Z$ (e.g. B which falls outside of $\underline{Y}$, and therefore in $\underline{Z}$ ), it follows that some $X$ is both $Y$ and $Z$. Thus, even if, generally speaking, nothing would follow from these premises, nonetheless in a continuum all this may be inferred from the premises thanks to the peculiar nature of continuity. ${ }^{90}$

89 "Et in genere, si linea aliqua continua erit in aliqua superficie, sitque partim intra partim extra ejus superficiei partem, hujus partis peripheriam alicubi secabit. Et si superficies aliqua continua sit partim intra solidum aliquod partim extra, necessario ambitum solidi alicubi secabit” (GM VII, p. 284).

90 "Hoc autem aliquo calculi genere etiam exprimere possumus, ut si alicujus extensi pars sit $\underline{Y}$ et unumquodque punctum cadens in hanc partem $\underline{Y}$ vocetur uno generali nomine $Y$, omne autem punctum ejusdem extensi cadens extra eam partem vocetur uno generali nomine $\mathrm{Z}$, adeoque totum extensum extra 
This rather abstract and almost set-theoretical presentation of continuity was Leibniz's final accomplishment in this field of research. He continued throughout his life to restate that Euclid's proof of Elements I, 1, was in need of a continuity principle. ${ }^{11}$

\section{\$7. The composition of the geometrical continuum.}

I would say that the most important logical progress made by Leibniz with his new definition of continuity consists in the fact that this latter is a fully structural definition. We have seen that in the early modern era continuity was often simply assumed to be a monadic property that bodies or figures may or may not possess-a useless notion in mathematics, which in many respects assumed continuity as a primitive, unanalyzable concept. The original Aristotelian conception of continuity was relational but it was not structural. The idea that continuity (or even the structure of magnitude) may arise from the system of all possible parts of a whole and their reciprocal relations was never explored by Aristotle and he was therefore not able to (nor did he want to) express the notion of completeness. This is rather to be found in Leibniz's definition, where continuity is neither a property nor a relation but rather a system of relations (Leibniz would say: un ordre de relations) existing among all the (infinite, possible) parts of a whole. Continuity is a structure and a structure is something which lies, logically speaking, in an altogether different realm from that of objects or relations.

There can be no question but that Leibniz's structural definition of continuity emerged out of his general views on mathematics, and these were themselves views which leaned toward structuralism in several fields-and in geometry in particular. In this respect, his celebrated definition of space as an order of (situational) relations opened up the way for him to an account of continuity along the same lines. The focus on the positional properties of things in space made it possible, for the first time, to conceive of continuity not as a monadic predicate or as a binary relation but rather as a system of such relations. I would, therefore, contend that the birth of such a notion of continuity constitutes one of the important consequences of the thematization of space as the object of geometry in the $17^{\text {th }}$ Century and in Leibniz's work in particular.

Nevertheless, it is very important to emphasize that Leibniz's definition of continuity, though indeed articulated in terms of a system of relations, is not articulated in terms of a

illam partemn $\underline{Y}$ sumtum vocetur $\underline{Z}$. patet puncta in ambitum partis $\underline{Y}$ cadentia esse communia ipsi $\underline{Y}$ et ipsi $\underline{Z}$ seu partim posse appellari $Y$ et $Z$, hoc est dici posse aliqua $Y$ esse $Z$ et aliqua $Z$ esse $Y$. Totum autem extensum utique ex ipsis $\underline{Y}$ el $\underline{Z}$ simul componitur seu est $\underline{Y} \oplus \underline{Z}$, ut omne ejus punctum sit vel $Y$ vel $Z$, licet aliqua sint et $\mathrm{Y}$ et $\mathrm{Z}$. Ponamus jam aliud dari extensum novum, verbi gratia AXB existens in extenso proposito $\underline{Y} \bigoplus \underline{Z}$, et extensum hoc novum vocamus generaliter $\underline{X}$, ita ut quodlibet punctum sit $X$, patet ante omnia omne $\mathrm{X}$ esse vel $\mathrm{Y}$ vel Z. Si vero ex datis constet aliquod X esse $\mathrm{Y}$ (verbi gratia A quod cadit intra $\mathrm{Y}$ ) et rursus aliquod $X$ esse $Z$ (verbi gratia $B$ quod cadit extra $\underline{Y}$ adeoque in $\underline{Z}$ ), sequitur aliquod $X$ esse simul et $Y$ el $Z$. Unde cum alias in genere ex particularibus hoc modo nihil sequatur, tamen in continuo ex iis tale quid colligitur ob peculiarem continuitatis naturam” (GM VII, pp. 284-85).

${ }^{91}$ See Leibniz letter to Schenk of November 21"st, 1712: “J'ai trouvé encor d'autres defauts dans les demonstrations d'Euclide: par exemple dans la prop. première du premier livre, il suppose que les deux cercles se rencontrent, sans l'avoir prouvé, ou sans en avoir fait un axiome” (DE RISI 2007, p. 621). 
system of situational relations. The system of relations in question here is rather a system of mereological relations and the notion of situs never appears in the definitions of continuity found in the Specimen geometriae luciferae or the In Euclidis $\pi \rho \tilde{\omega} \tau \alpha$. In particular, relations of order are generally subsumed by Leibniz under the general heading of "situation" and his definition of continuity, in contrast to Dedekind's, is not based on ordering relations. ${ }^{92}$

The main reason for this definitional strategy was probably Leibniz's strong commitment to the traditional Aristotelian definition of continuity, which was itself mereological. This, in its turn, was grounded in Aristotle's and Leibniz's further commitment to a definition of quantity as a mereological structure (quantity is for them something which has parts). Most of all, however, Leibniz's mereological definition of continuity is rooted in his own deeper agreement with Aristotle regarding the composition of the continuum.

Aristotle had denied that there can be a continuity of points (given his definition of continuity) and Leibniz himself cannot but endorse such a view. Leibniz's points are not homogeneous with the whole, and are therefore not parts of this latter. Thus, they cannot engender any mereological structure and a simple collection of points (without any further structure) cannot be continuous according to Leibniz's definition of the term. It should be noted, in fact, that Leibniz's definition of continuity is mereological all the way down, in the sense that it is expressed by a system of relations among parts, which are themselves continuous and (given density) composed of other parts, on and on to infinity. Such a definition is neither inconsistent nor circular and the fact that the parts are continuous (as a consequence of the continuity of the whole) only means that a continuum is not reducible to simpler, non-continuous elements. One has to begin, so to speak, with a continuous whole. This was the classical Aristotelian way out of the labyrinthus continui: namely, stating that one cannot compose any extension from unextended things, and that points and other unextended elements are just abstractive limits (boundaries) of an originally given continuous extension.

In the overwhelming majority of his writings, both public and private, and running from his young years up to the very last months of his life, Leibniz simply remained faithful to the classical idea that unextended elements cannot compose extension, and that a set of points cannot be continuous. He was therefore convinced that continuity could not be constituted by a situational structure such as the one expressed in the above-mentioned definition of a circle. He did not attempt to reduce the elements of geometry to points and situational relations alone, taking continuity to be a derivative notion that could be defined starting from these latter. Rather, he permitted extension itself, or continuity, to count among the basic elements of geometry: on a par with situational relations. For example:

When one meditates on geometry, two concepts come first of all to mind: namely, absolute space itself, in which nothing can be considered but extension; and the point, in which nothing can be considered but situation. Space has no situation, and a point has no extension. Space is infinite, and a point is indivisible. Space is the locus of all points. Midway between point and infinite space is the finite extensum, which has both extension and situation. A point

\footnotetext{
92 See for instance Leibniz’s Fifth Letter to Clarke, $\$ 54$, in which Leibniz puts together the two notions (ROBINET 1957, pp. 150-51). The idea is recurrent also in his mathematical papers.
} 
outside of it can always be assigned. And it lies itself in infinite space, and bears a situation in respect to any other extensum... ${ }^{33}$

Here, extension and situation (found respectively, in their pure forms, in space and in points) are the original elements of geometry. We may add that Leibniz's standard definition of extension is that of a "co-existent continuum" (as opposed to the successive continuum of time). ${ }^{94}$ The notion that he really needs to supplement situs with, then, is that of continuity. This is clearly stated elsewhere:

Extension indeed arises from situation but adds continuity to situation. Points have situation, but do not have continuity, nor do they compose it... ${ }^{95}$

This dichotomy between situation and continuity recurs extremely frequently in Leibniz's writings, and has many ramifications outside the domain of geometry, extending into metaphysics itself. In a sense, the entire debate on corporeal substances in Leibniz's late metaphysics - namely, that on whether monads (and their structure) are themselves sufficient to compose bodies or need something further added - may be read from this perspective. We will not follow these developments here but it is important to see that the irreducibility of continuity to a situational structure is pervasive in Leibniz's thought.

Nonetheless, an important difficulty still lied ahead for an early modern mathematician, and for Leibniz in particular: a difficulty that stemmed from the enormous developments in mathematics that had occurred in the centuries elapsed since Aristotle and Euclid.

We have seen, in fact, a few excerpts from Leibniz's characteristica geometrica in which spheres, circles, planes and lines are defined as collections of points satisfying certain geometrical conditions. Leibniz had even introduced into his calculus a symbol (the short line over the letters) for a universal quantification that ranges over points. Even more, the general example given by Leibniz himself in the Specimen geometriae luciferae in order to formalize his newly found notion of continuity in terms of his geometrical characteristics also quantifies over points, rather than over parts. Here, as everywhere else in Leibniz symbolic treatment of geometry, geometrical figures are defined in a (naïve) set-theoretical way rather than in mereological form, with these collections of points nonetheless being claimed to have to be considered as continuous.

\footnotetext{
93 "Ordine meditanti de rebus geometricis ante omnia occurrent duo, Spatium scilicet ipsum absolutum, in quo per se nihil aliud considerari potest quàm extensio; et punctum in quo nihil aliud considerari potest, quàm situs. Spatium non habet situm et punctum non habet extensionem. Spatium est infinitum et punctum est indivisibile. Spatium est locus omnium punctorum. Medium inter punctum et spatium infinitum est extensum finitum, $\&$ id extensionem habet et situm. Assignari potest aliquod punctum extra ipsum. Ipsum inest spatio infinito, ad aliud quodlibet habet situm". From a paper from the mid-1680s, in LH XXXV, I, 5, Bl. 49, in DE RISI (2007, p. 624).

${ }^{94}$ This definition is widespread. It can be found, for instance, in $\$ 17$ of the Characteristica geometrica from 1679 (GM V, p. 147). It is discussed in strongly anti-Cartesian terms in the 1680s, for instance in the Generales inquisitiones (A VI, 4A, n. 165, p. 745), but it recurs also in Leibniz's late years (for example in the letter to De Volder from December 31 ${ }^{\text {st }}, 1700$, in GP II, p. 221).

${ }^{95}$ Leibniz to Des Bosses, April 24 ${ }^{\text {th }}, 1709$ (GP II, p. 370).
} 
It may be remarked that Leibniz could have been in good company, because his views on the impossibility of composing the continuum out of points were quite widespread in the $17^{\text {th }}$ Century, and yet anyone working with Cartesian algebraic geometry (and then the geometry of transcendental curves) had to say that a curve is the collection of points expressed by the solutions of an equation. It should be remarked, however, that in early modern mathematical epistemology the connection between algebra and geometry was conceived of as quite extrinsic. Almost no one had yet dreamt of identifying an equation with a curve. Algebra was not a way of expressing geometry by symbols but rather a tool that a mathematician might use to solve a geometrical problem. In this respect no one took seriously (i.e. treated as a foundational statement) the apparent algebraic implication that curves were made of points. Curves were rather geometrical objects, which were not collections of solutions of equations and which received their continuity by their definition or by their generation through a continuous motion (for example), be it in imagination only or actually practically performed using compasses, strings and sliding rulers. Algebra, intended as a useful formalism to investigate certain properties of a curve, had nothing to say about the true nature of this latter.

Then again, Leibniz's characteristica geometrica was first conceived precisely in order to surpass the shortcomings of the application of algebra to geometry. It is a characteristica propria because it should be able to express the content of geometry without any extraneous element. The constant and variable letters do not range over numbers, as in Cartesian algebra, but straightforwardly over points, and the relations are those of congruence (or similarity), that is to say, basic geometrical relations. In fact, the definitions of curves offered by Leibniz's symbolic treatment (i.e. by taking the circle as $\underline{Y}: A . B . C \simeq A . B . Y$ ), which employs only elementary situational relations, should even express the essential definition of said geometrical objects. ${ }^{96}$ In this sense, such definitions should express the innermost essence of the geometrical figures, which therefore should actually be considered as a collections of points.

Here we see at work Leibniz's new structural conception of geometry. While it is true that a circle is a collection of points, it is also a collection of situated points (this is expressed in the above-mentioned formula by the dot between letters-meaning a relation of situs). In fact, a circle is a certain structure of points, which have an infinity of spatial relations to one another, as expressed by the formula. Once again, it is of paramount importance to realize how different such a conception of a geometrical figure was from the standard $17^{\text {th }}$ Century notion of a geometrical object: the latter may well have relations with other objects and might even be analyzed in a finite set of components (as, for instance, in the case of the three straight lines forming a triangle), but, contrary to Leibniz's new conception of space and geometrical figures, it cannot be entirely resolved into a structured set of relations.

I think that this structural and almost set-theoretical conception of geometry that we find in Leibniz's writings may explain the fact that Leibniz could not be entirely satisfied with the classical Aristotelian views on the composition of the continuum, in so far as they entailed a multi-sorted, non-structured ontology of geometrical objects. As a matter of fact, we may spot another trend in Leibniz's mathematical writings, which is less represented but

\footnotetext{
${ }^{96}$ I have briefly investigated the notion of an essential definition in Leibniz's geometry in my DE RISI (2015, pp. 31-40).
} 
extremely important, in which he attempts different solutions to the old problem of the composition of the continuum.

We know that in his young years (around 1670), Leibniz was still (somewhat naively) attempting to conceive of extension as composed of indivisibles. He abandoned this view in the Parisian years, to embrace the above-mentioned classical solution to the problem of continuity, which is expressed by a stark dichotomy between situation and extension. It should be mentioned that still in the late 1670 s he was still thinking about whether continuity could arise by some peculiar situational structure of points, so that extension might be considered to be composed of situated points after all. In his handwritten notes to Henry More's book on the Immortality of the Soul, in which More argues in the usual Aristotelian way about the impossibility of composing extension out of points, Leibniz remarks:

This line of reasoning - namely, that extension is not composed of points because it would thereby be composed by nothings of extension - does not seem very certain. Because the points are something more than nothings, having a situation. ${ }^{97}$

The passage is quite elliptical, but it is hard not to see in it a hint that extension may be produced by points as a system of situational relations.

In the following years, Leibniz's conception of space as a system of situational relations was strengthened and developed. Since a point is defined (as we have seen) simply as an object the only property of which is to be considered as an element of a situational relation, it seems obvious to think of space as a system of situated points. In this respect, a close comparison can be drawn between Leibniz's mature definition of space and our present-day notion of a metric space, in which extension results not from a "material" accumulation of an infinity of unextended points but rather from a "formal" structure endowed by the system of all distances (i.e. situational relations) among its points. ${ }^{98}$ Nevertheless, as the above-mentioned texts show, Leibniz seemed to deny that a simple situational structure might engender continuity and restated the divide between situation and extension.

In the 1690 s, however, probably prompted by a renewed interest on his part in a mathematically sound definition of continuity, Leibniz expressed once again with great clarity the idea that extension should be considered as a structure of points (or of other lower-dimensional indivisibles) rather than as an unanalyzed "gunk". We have already mentioned the passage in the Specimen geometriae luciferae in which Leibniz directly declared to be "continuous" a figure composed of a collection of lower-dimensional objects

\footnotetext{
${ }^{97}$ The passage most likely dates from the late 1670s and thus predates Leibniz's definition of continuity. Leibniz had already embarked, however, on his project of analysis situs and had already given his definition of space as a system of relations. The original text reads: "De plus le raisonnement ne me paroist pas trop asseuré, que l'étendue n'est pas composée de points, parce qu'elle seroit composée de riens d'étendue. Car les points sont un peu plus que riens, ayants une situation" (A VI, 4B, n. 331, p. 1678). We may add that the standard objection here - namely, that a collection of points cannot compose extension, since adding a point to other points would be "adding a nothing to a nothing" (velut si nihil nulli iungas) - is to be found in Boethius (De institutione arithmetica, II, 4; ed. Friedlein, p. 87).

${ }^{98}$ I have briefly described Leibniz's constitution of a metrical space (without mentioning continuity) in my DE RISI (2019).
} 
arranged in a certain order (a spheroid made up of continuously varying ellipses). In a few further passages of the great Dynamica from 1689-1690 Leibniz dealt with similar examples in which a cylinder is seen as constituted by an infinity of concentric cylindrical surfaces (he even spelled out the singular point of such a foliation):

I say, therefore, that the solid is constituted by these surfaces: not so much by reason of the fact that it is composed by them as by reason of the fact that these surfaces absorb all of its points and lines, with the possible exception of a few of them, which are determinate. The cylindrical surfaces inscribed in the cylinder absorb all of its points and lines, with the exception of the axis. ${ }^{99}$

Elsewhere in the same work, Leibniz considered a surface in motion to be made up of an infinity of lines sharing a common motion and added once again that such a collection of lines did not compose the surface but nonetheless (in some way still to be explained) constituted it: "constitui, dico, non componi". He further claimed that bodies are constituted by points, that is to say, they are nothing but sums of points ("nihil aliud sunt quam summae punctorum"). ${ }^{100}$

We may note that in these passages situation is no longer mentioned as the structural element needed to enforce continuity and, in fact, Leibniz did not explicitly propose any foundation for the operation of constitution. Leibniz's studies on geometrical continuity ought, therefore, to have explained which further principle, besides situation, was needed in order to obtain a proper constitution of the continuum - something that needed to be clearly distinguished from the standard Aristotelian discussion on the composition of the continuum.

While, however, the Dynamica had been written a few years before the Specimen geometriae luciferae, I would argue that after the geometrical breakthrough of the mid1690 s it is clear that such constitution may be characterized by the mereological structure added to the situational structure. In this respect the mutual irreducibility of situation and continuity is now revealed to be grounded in the interaction of two different structures: a situational structure on the one hand, which is often represented as a system of distances between points and that in any case has points as its basic elements and by which we may define geometrical objects and shapes; and a mereotopological structure on the other, by which continuity is defined and the elements of which are (extended) parts rather than points. Leibniz's claim that geometry is only possible by means of extension and situation together hereby becomes the idea that two different geometrical structures interact with one another. His claim of the irreducibility of extension to situation may be further explicated

99 "His autem superficiebus solidum constitui dico, non quod componant, sed quia omnia ejus puncta absorbent, forte quibusdam determinatis, ubi superficies cylindricae cylindro inscriptae absumunt omnia ejus puncta et lineas, praeter axem” (GM VI, p. 317; cf. also p. 319 for a similar use of “constituere").

100 The expression "constitui, dico, non componi" comes from GM VI, p. 370, where Leibniz discussed the surface constituted by lines and then repeated the above-mentioned example with the cylinder. Further on in the same work (GM VI, p. 399), Leibniz also mentioned a pyramid constituted of smaller and smaller rectangles. A similar passage, in which rectangles constitute a more complex solid figure, is to be found in GM VI, p. 415. Finally, he also mentions bodies constituted by points in GM VI, p. 498: "et quod de punctis duobus, id de quibuscunque veram esse ostendimus, adeoque et de mobilibus quibuscunque quae per puncta constituntur, seu nihil aliud sunt quam summae punctorum, hoc est corporum sufficientis ad evitandum errorem dato minorem parvitatis". I thank Andrea Costa for bringing to my attention some of these passages. 
as the impossibility of accounting for the mereological structure as emergent from the underlying situational (i.e. metric) structure. In general, situational relations obtain among points and are, in this sense, first order relations. Even when Leibniz refers the situation of an extended figure to that of another extended figure, this generally means that there are certain situational relations between the points of the two figures in question: that is to say, a situational relation between figures is reducible to situational relations between individual points. On the other hand, continuity is defined by an irreducible appeal to parts and therefore needs to refer to (and quantify on) the elements of a further, second-order, structure: namely, the mereological one, constituted by sets of points rather than points. In this respect, while it is true that we can describe space and figures in purely situational terms, the facts that they have parts, which are collections of points, and that these parts themselves have a structure (a mereological one) is something that is irreducible to situational relations. In modern terms, Leibniz's ontology of space needs both elements (i.e. points) and sets (which give rise to parts). ${ }^{101}$

We may also add that parts must be regarded as actually infinite collections of points. There is no doubt, in fact, that before the $19^{\text {th }}$ Century Leibniz was one of the very few philosophers who envisaged the possibility of treating the actual infinite in mathematical terms. The very fact that he devised a peculiar notion of an actual and yet syncategorematic infinite in order to deal with this notion, shows the importance of the actual infinite in Leibniz's mathematical studies. The present issue seems to be a high point of Leibniz's new approach to infinite collections of elements, that had few matches before Dedekind and Cantor. ${ }^{102}$

Here is the real divide between Leibniz's conception and the classical, Aristotelian one. For Aristotle, an extended whole is just a different kind of being than a point (or a boundary in general) and one has to accept a two-sorted (or many-sorted) ontology of extended and unextended things. By contrast, there is a sense in which Leibniz's extended wholes are "constituted" by points, since the parts required to possess continuity are nothing but collections of points. In the same way, we have seen in a quotation from the Specimen geometriae luciferae that a solid body may be conceived of by Leibniz as constituted by a continuous family of surfaces. The continuity of such a family is not given by the reciprocal situation of the elements, and Leibniz is adamant that the set formed by these latter is continuous even without its having to be geometrically structured into a solid figure, or placed in space. Continuity is rather given by a further condition on the possibility of putting them into a regulated correspondence with the points of a continuous segment. There is a continuous map between a family of surfaces constituting a body, and the collection of points constituting a segment. The segment itself (and therefore also the body) is continuous thanks to its mereological structure, according to the definition of continuity given in the Specimen. ${ }^{103}$

\footnotetext{
101 There might by some exceptions to this rule in a few geometrical writings, in which the situational relation cannot but apply to the figure as a whole. I have given a few examples of this attitude in my Leibniz on the Parallel Postulate, and will not discuss it further here.

${ }^{102}$ On the topic, see Arthur's fictional dialogue between Leibniz and Cantor in this volume.

103 We will not deal here with the most difficult problem of the continuity of time in Leibniz's philosophy. We may notice, however, that a mereological approach to continuity as the one sketched above might in fact allow Leibniz to claim that time is continuous, and that it is nonetheless a collection of instants. The latter
} 
Leibniz's ontology, then, is, in a sense, as two-sorted as the Aristotelian one: there are points, endowed with a situational structure; and parts (or sets of points), endowed with a mereological structure. Aristotle's "substantialistic" view on the composition of the continuum has thus been transformed into a (similarly expressed) structural approach to the same problem. In this sense, extension (as a coexistent continuum, according to Leibniz's definition) has been dissolved into a system of parts. ${ }^{104}$

We may now attempt to offer an explanation of Leibniz's thought regarding continuity in his characteristica geometrica and in geometry in general. A formula such as $\underline{Y}$ : A.B.C $\simeq$ A.B.Y, expressing the "equation" of a circle does not, and cannot, express the continuity of this latter. It only states the situational relations obtaining among the points that give rise to the figure of a circle (e.g., a set of points equidistant from a center). The formula, however, quantifies on the points of space and states that a circle is constituted by all these points. Whether the collection of all these points is rich enough to, and structured in such a way as to, guarantee continuity-this is an altogether different question, and depends on space itself as the collection of all points. The situation here is similar to that in ordinary algebra, where the circle equation $x^{2}+y^{2}=1$ would produce Dedekind-complete or incomplete circles depending on whether the variables range over $\mathbb{R}$ or, say, the field of rational numbers $\mathbb{Q}$; and this is something that the equation itself cannot express.

Leibniz holds, therefore, that the continuity of space is the source of the continuity of the circle, which is defined as a collection of points. This is well expressed in the abovementioned passage from the 1680s in which Leibniz immediately connects extension (and therefore continuity) to space, while situation is seen as an original property of points (or collections thereof). Space, however, is the source of the continuity of the circle not in the sense that it contains "points enough" to be continuous (i.e. complete), but in the sense that it has a mereotopological structure which makes it continuous. Such a structure is not and cannot be expressed as a system of situational relations among points, and therefore escapes the expressive power of a characteristica geometrica, by which we define the circle. Being a part of space, however, the circle inherits its mereotopological structure and acquires (so to speak) parts, boundaries, and situational relations between these latter. In this way, the circle acquires continuity. The whole process may be seen as a kind of embedding which induces a mereotopological structure on the subset.

We may note that such an embedding is only possible insofar as space itself is not just a mereotopological structure but also a situational system of points, and in particular the system of all situated points (otherwise a circle, defined as a system of situated points, could

statement recurs in Leibniz's writings, and its formulation is especially striking in a draft from 1695-that might have been composed, therefore, in the same months of the Specimen. In it, Leibniz simply recognized the problem: "Tempus vero videtur necessario componi ex instantibus, quia duo instantia simul existere non possunt; itaque existit tantum instans praesens; [passatum] extitit, futurum existet. Video tamen nondum hinc sequi quod linea componatur ex infinitis punctis, sed tantum quod infinita puncta sunt in linea. Verum ecce difficultatem" (LH I, I, Bl. 24r., edited by MUGNAI 2000, p. 135). We may notice that a situational definition of the continuum, would not work in order to ground the continuity of time, since instants have no situs (cf. C 541).

${ }^{104}$ In the Nouveaux essais, I, III, $\$ 6$, Leibniz plainly states that the notion of extension is posterior to (and possibly generated by) the notions of whole and parts: “je crois plustost que l'idée de l'étendue est posterieure à celle du tout et de la partie" (A VI, 6, n. 2, p. 103). 
not embed in space). The interplay between the situational structure and the mereotopological structure, therefore, occurs in space.

\section{\$8. The continuity of space.}

This latter, very important mathematical claim namely, that the continuity of a figure in space must be grounded in the continuity of space itself - was rather new, indeed almost unprecedented, in the $17^{\text {th }}$ Century, when geometry was still largely regarded as a science of figures rather than a science of space. It is nonetheless perfectly in line with the whole Leibnizian project of an analysis situs, that is to say, a new geometrical science which conceives of space as a structure of situational relations (an ordre de situations), and takes it to be the proper object of geometrical investigations.

Leibniz's epistemological attitude towards space and figures may be briefly sketched as follows. ${ }^{105}$ In geometry, we are free to begin our enquiry by giving any arbitrary definition of a given figure. We may, for instance, follow Euclid in defining the circle as the curve equidistant from a given point (the center). After giving such a nominal definition, however, we should prove the possibility of the defined object (i.e. the internal consistency of the notion), and therefore transform the nominal definition into a real definition which can be actually employed in mathematical reasoning (since a merely nominal definition, which might possibly be inconsistent, would endanger the whole process of reasoning). Such real possibility may be proven, in principle, using any means might be available to us; in practice, however, most mathematicians in the early modern age, including Leibniz, thought that the easiest way to provide evidence of the possibility of a geometrical object was to generate it by giving a construction rule for it. In the case of the circle, this would amount, for example, to saying that it is generated by the rotation of a segment around one of its endpoints. Leibniz, however, here asks something more: the circular motion of the segment itself should be proven to be possible; otherwise we are just assuming, rather than proving, the possibility of the circle itself. The possibility of such a motion, though, may only be grounded, for Leibniz, in a property of space itself. Commenting on Euclid's Third Postulate, he wrote in the In Euclidis $\pi \rho \tilde{\omega} \tau \alpha$ :

Postulate 3: To describe a circle with any center and radius. This can be done in a plane by the motion of the radius while one of its endpoints remains still. But that a straight line can be moved while one of its endpoints stands still can be derived from the fact that the plane, or space, is uniform... ${ }^{106}$

\footnotetext{
${ }^{105}$ I have offered a lengthier treatment of the subject in my DE RISI (2015).

${ }^{106}$ The original passage reads: "Postulat. III. Quovis centro et intervallo circulum describere. Id in plano efficit motus radii uno puncto immoto. Posse autem moveri rectam uno puncto immoto ex eo colligitur, quod spatium planumve uniforme est, et quod versus unam est plagam, potest etiam versus aliam sumi quamcunque" (GM V, p. 206). Similar statements recur, however, frequently in Leibniz's works on geometry and can be found, for instance, in his paper from 1676 on Generatio quidem rectae et circuli (in ECHEVERRÍA, PARMENTIER 1995, p. 66), his essay Uniformis Locus from 1692 (in DE RISI 2007, pp. 582-85), his reading notes to Arnauld's Nouveaux Elémens de géométrie from 1695 (in DE RISI 2015, pp. 146-51).
} 
The uniformity of space, here mentioned just in passing, is a property that Leibniz characterized elsewhere as a sort of isotropy (in modern terms), being the one grounding free rigid motion and rotations in space. The important mathematical and epistemological point, in any case, is that the very possibility of a geometrical figure is to be grounded, in the last analysis, in a property of the space in which it is embedded, and in this sense the true object of investigation of a perfected analysis situs should be space itself and its properties.

It is now easy to see that, since uniformity of space is necessary in order to state the possibility of a figure the points of which are all equidistant from a given point, the continuity of such a figure - which is not, for Leibniz, entailed, as it was for many of his contemporaries, by the simple notion of motion - should be grounded in a further property of space itself, that is to say, in its own continuity. This means that a circle is, in the last analysis, only possible as a figure, and will only intersect with other circles when crossing them (as in Elements I, 1), thanks to the uniformity and continuity of space itself. Such properties are themselves defined in structural terms, since space is nothing more than a system of relations. We have already seen, however, that uniformity is a situational property in the strict sense, and that it must depend on the structure of situs relations (i.e. broadly, on the structure of space conceived of as a system of distances, or as a metric space in abstract terms), while continuity is defined rather in terms of parthood relations, and therefore depends on the (independent) mereological structure of the same space.

This latter geometrical analysis, which relates back all the properties of a figure to the properties of the underlying space, was not, however, to exhaust the aims of Leibniz's analysis situs. It is well known, in fact, that Leibniz also embarked on the grand epistemological project of a kind of logicism in geometry. He wanted to show that the whole of geometry, and all its theorems, could be proven by logical laws alone and were ultimately grounded in the Principle of Contradiction, so that any deviation from the theorems of Euclidean geometry would not count as the consequence of an alternative system of axioms but rather as a logical inconsistency. ${ }^{107}$ Given the preceding discussion, it should be clear that Leibniz could hope to achieve such a goal by proving, using logical means, that space itself cannot but possess a number of geometrical properties, such as the above-mentioned uniformity and continuity, on which the whole of classical geometry could rest. This proof, in turn, had to be grounded exclusively in the definition of "absolute space" as the order of all possible situations, and on a few metaphysical considerations establishing the necessity of such a structure.

We will not follow here the details of this geometrical and philosophical program, which was clearly doomed to fail. We may remark, however, that, if extracting such complex geometrical properties as uniformity (i.e. isotropy) or three-dimensionality out of a general notion of total situational order was surely a difficult (and in fact, an impossible) task, even greater difficulties stood in the way of attempting to prove continuity from such a definition. Because, as we have noted, the mereological structure needed to define continuity cannot, in principle, be reduced to the situational structure by which space is logically defined. In fact, however, Leibniz's "logicism" in geometry had a hybrid nature and rested not only on logical laws but also on several metaphysical and phenomenological

\footnotetext{
${ }^{107}$ For a more nuanced and complex account of Leibniz's logicism, see the essay by Valérie Debuiche and David Rabouin in this volume.
} 
considerations. Leibniz claimed that space is somehow "ideal" and, while the exact import of the latter notion is difficult to establish, this certainly means that space is, in a certain way, a product of the mind (as an abstraction from physical extension, or perhaps as a form of intuition in an almost Kantian sense). This, in turn, implies that several properties of space may be derived not just from its logical definition (the order of all possible situations), but also from the operations of the mind that are necessary to produce it. In this way, Leibniz opened the way to a phenomenological foundation of geometry itself. ${ }^{108}$

The philosophical discourse of phenomenology enters into the foundations of geometry especially in relation to continuity. This can hardly be surprising, since the mereological structure cannot have a purely logical source in the notion of a situational order. In particular, Leibniz defines sensible (as opposed to intellectual) knowledge by stating that the former is a confused apprehension of reality. Confusion, in turn, is tantamount to a certain degree of indeterminacy, which causes us to perceive as homogeneous things that are not in fact so. For instance, we do not perceive all the infinite, actual divisions of matter and our sense-experience ceases once we have arrived at a certain degree of detail, leaving an undifferentiated extension beyond that point. The actually divided parts of matter (or physical space) are confused with one another, becoming an undifferentiated extension that has only indeterminate parts. In short, and without entering into the difficult and complex details of Leibniz's phenomenological theory, such (necessary) indeterminacy of perception must form the ground of the continuity of space. Geometrical space is a kind of idealization of the sensible medium (there would be no space without sensibility), and therefore retains traces of the structure of sensibility itself as the organ of confused perception. Ideal space is simply totally undetermined and homogeneous, since sensibility is the faculty producing such indetermination. The indeterminacy of space, in particular, is manifested (as we have seen above) in the indeterminacy of its parts. We remember, on the other hand, that Leibniz's "metaphysical" definition of continuity was grounded simply on the indeterminacy of parts. Therefore, "absolute space", i.e. the one, original, ideal geometrical space, is continuous. ${ }^{109}$

We do not need to enter into the details of Leibniz's phenomenology in order to understand that the proof that he was attempting to give fell short of its goal. In fact, even if we were to follow Leibniz through his complex epistemological theory of sensibility and idealization, we would thereby only be grounding the continuity of space on a definition of continuity as indeterminacy of parts - which was abandoned by Leibniz himself in his geometrical writings and has no definite mathematical meaning. This definition was, in fact, just the standard (and much easier) metaphysical definition of continuity that the Specimen geometriae luciferae attempted to surpass.

\footnotetext{
${ }^{108}$ I have offered a detailed treatment of Leibniz's phenomenology in relation to geometry in my DE RISI 2007.

${ }^{109}$ For further details I cannot but refer again to Geometry and Monadology. I may add here a nice quotation by Leibniz from an early essay on Divisio terminorum: "Extensionem vocamus quicquid omnibus simul perceptis commune observamus; et extensum vocamus cujus perceptione plura percipere possumus simul; idque indefinita quadam ratione, unde extensum est totum continuum cujus partes sunt simul et habent situm inter se, ipsumque totum rursus eodem modo se habet tanquam pars respectu alterius. Totum continuum est cujus partes sunt indefinitae, tale est ipsum spatium abstrahendo animum ab his quae sunt in ipso. Hinc tale continuum est infinitum, ut tempus et spatium. Cum enim ubique sibi simile sit, quodlibet totum erit pars" (A VI, 4A, n. 132, p. 565).
} 
Leibniz also attempted other phenomenological deductions of the continuity of space. In his Characteristica geometrica from 1679, he made the following remarks:

(60) Between any two congruent objects, infinite other congruent ones can be taken; in fact an object cannot move to the place of another and still preserve its own shape except by passing through other congruents.

(61) Therefore, a line can be drawn from any point to any other. In fact, any point is congruent with any other point.

(108) If two objects are perceived simultaneously in space, then, by this very fact, the path from the one to the other is also perceived. And by virtue of the very fact that they are congruent, the path from the one to the place of the other is also thought. ... Or, to put it yet another way: we perceive that a certain object can move, and thus come to be either in one place or in another one; but, since it can neither exist in a plurality of places at the same time nor move in just one instant, we perceive this place as continuous. ${ }^{110}$

Leibniz restated similar geometrical-phenomenological claims about continuity in his late years. ${ }^{111}$ In such passages, it seems that continuity of space is simply tantamount to arcwise connectedness, since Leibniz discusses the possibility of tracing a line (in other texts, a straight line-geodesic connectedness) from any point to any other point. Therefore, however fascinating we may find such texts, and however sound we may judge Leibniz's phenomenological deduction of such a property to be, it is not a matter here of continuity as Dedekind-completeness, and it is not useful for grounding Euclid's results.

Lastly, in some other texts Leibniz stressed the fact that the very notion of an "absolute" or "universal" space, meant as the system of all possible situations, implies that such a space contains "all points" (since a point is just an abstract situated element): Spatium Universum est locus omnium punctorum. This last statement is also sometimes reshaped into phenomenological terms, so that Leibniz can attempt to prove that absolute space encompasses the totality of situational relations by stating that the perception of any situational relations entails the perception of any other. In any case, Leibniz stated explicitly that such a universal or absolute space had necessarily to be continuous:

\footnotetext{
${ }^{110}$ The first two sections have been published in GM V, p. 161: “(60) Inter duo quaevis congrua assumi possunt infinita alia congrua, nam unum in locum alterius servata forma sua transire non posset, nisi per congrua. (61) Hinc a quolibet puncto ad quodlibet punctum duci potest linea. Nam punctum puncto congruum est”. The latter sections, however, appear to be grounded only at the end of the essay, in $\$ 108$. Since, however, this section is more metaphysical than geometrical, Leibniz himself had suggested (in the margins of the manuscript) excising $\$ 108$ from the mathematical essay, and this was actually done by the $19^{\text {th }}$ Century editor of GM V. The last section was eventually published in ECHEVERRÍA, PARMENTIER (1995, pp. 228-30): "Cum duo simul in spatio esse percipiuntur, eo ipso percipitur via ab uno ad aliud. Et cum sint congrua, eo ipso concipitur via unius in alterius locum. Sunt autem duo puncta congrua. Itaque quod percipitur, duobus punctis simul perceptis, est Linea, seu via puncti. ... Sive quod idem est, posse moveri, sive posse tam in uno loco quàm in alio esse, et quia non potest simul esse in pluribus locis, nec moveri in instanti, ideò locum illum percipimus ut continuum”.
}

${ }^{111}$ In the Initia rerum mathematicarum metaphysica from 1715, in GM VII, p. 25. 
Every place is in the same absolute space. Absolute space is continuous, otherwise some place could be interposed which would not be in it. ${ }^{112}$

This notion of continuous space as the totality of all points has in fact some relation to the notion of completeness, which also asserts something about the existence of a certain totality of ordered points. Nevertheless, the whole difficulty consists in stating what exactly "all" means here and it was to solve this difficulty that Dedekind's definition was first conceived. On the other hand, Leibniz's definition may bear a somewhat closer resemblance to the (quite problematic) definition of Linear Completeness given by Hilbert in the Grundlagen. Once again, though, Leibniz's philosophical proof is too general, and too vague, to provide an exact meaning for this notion.

In short, we may say that Leibniz's logicist program in geometry required a proof that there is just one possible space and that this space is continuous. In turn, the continuity of space, which could not be proven (in Leibniz's terms) from the logical definition of space, forced Leibniz to venture into a different domain, and to extend his logicist program in order to include a few phenomenological considerations. By such considerations Leibniz may have believed he had proven the continuity of space. But his notion of this latter's continuity had been formulated only with older, metaphysical notions (such as the indeterminacy of parts) or insufficient or vague mathematical claims (arcwise connectedness, totality of points). In the meantime, however, Leibniz had been able to achieve a remarkable mereotopological definition of continuity as completenessconnectedness which could be usefully employed in geometrical demonstrations. Such a definition, though, would have been difficult to apply to space itself using philosophical arguments: metaphysics and mathematics failed to weld together.

In this respect, the program of Leibniz's analysis situs was a failure especially in relation to continuity and he could not claim to have proven the logical necessity of the meeting of the two circles in Elements I, 1. Leibniz had perfected Euclid's proof by giving a viable mathematical definition of continuity, by which he could prove in a rigorous way that the two circles meet-provided that they are continuous. This was Leibniz's great accomplishment in the foundations of mathematics and may count as the first (although surely imperfect) grounding of a general theory of intersections. From our modern standpoint, no further discussion would be required, and we would be prompt to assume the continuity of the circles (or the continuity of the underlying space) as an axiom. Leibniz's epistemology, however, brought him to ask for more: to ask for a proof of the continuity of space itself that could eliminate the need for an axiom on continuity. Such a proof was a failure, for it could not be achieved, and exposed Leibniz's line of reasoning to

\footnotetext{
${ }^{112}$ The passages in which Leibniz defines space as the totality of points are numerous, and I will only refer here to the Scheda on situation and extension from 1695, in which Leibniz explicitly connects this array of problems with continuity (to be found in DE RISI 2007, pp. 588-89; the Latin quote above is taken from there); and to the essay Spatium absolutum... from 1714, from which the longer quotation is taken: "Spatium absolutum interminatum est quod in situ amplissimum est. Ideo omnis locus est in eodem spatio absoluto. Spatium absolutum est continuum, alioqui locus aliquis interponi posset qui in ipso non esset" (DE RISI 2007, p. 609). We may note that Leibniz considered complex numbers to be internally inconsistent, and therefore there is a sense in which the maximal number field had been for him that of real numbers: complex numbers cannot be taken as coordinates of possible situational elements. Given that he believed that he could prove the three-dimensionality of absolute space (DE RISI 2007, pp. 205-215), the "totality" of its points had to be modeled on $\mathbb{R}^{3}$.
} 
a number of incursions in the muddy waters of metaphysics, and to a few paralogisms attempting to connect together a phenomenological definition of continuity (or a bunch thereof) with his different, and quite good, mathematical definition of the same notion. Leibniz himself could not have been fully satisfied by his own efforts towards an analysis situs grounding a theory of continuity. But we, disenchanted about the possibility of a logicist program in geometry, may still appreciate Leibniz's outstanding results in defining continuity.

Leibniz's definitions and demonstrations were lacking the exactness, simplcity, or power that we find in similar (but much later) attempts by Bolzano and Dedekind. They are still remarkable, though, as they are probably the only ones in the modern age to ground continuity in a purely geometrical way. Leibniz lived in an age in which the foudation of mathematics were not found in number theory or analysis, but rather in geometry, and the Elements were considered to be the groundwork of the whole mathematics. Yet, we have seen that no other early modern mathematician ever attempted at a geometrical definition of continuity, and the latter had to wait for the deep transformation of mathematics that occurred in the $19^{\text {th }}$ Century, and eventually produced Dedekind's arithmetical analysis of cotinuity. In this respect, Leibniz's unstable mediation between the Euclidean tradition in the proper sense and the modern need for rigour remained an isolated, and soon forgotten, attempt at maintaining continuity between two ages of mathematics. 


\section{Bibliography}

M.L. AlcoBA (1996), Leibniz: Geschichte des Kontinuumproblems, "Studia Leibnitiana”, 28, pp. 183-198.

D.A. Anapolitanos (1990), Leibniz on Density and Sequentiae or Cauchy Completeness, in Greek Studies in the Philosophy and History of Science, ed. P. Nicolacopulos, Dordrecht, Springer, pp. 361-73.

R.T.W. ARTHUR, ed. (2001), Leibniz: The Labyrinth of the Continuum, New York.

R.T.W. ARTHUR (2013), Leibniz's syncategorematic infinitesimals, "Archive for the History of Exact Sciences", 67, pp. 533-93.

R.T.W. ARTHUR (2018), Monads, Composition, and Force: Ariadnean reads through Leibniz's Labyrinth, Oxford, OUP.

P. BeEley (1996), Kontinuität und Mechanismus. Zur Philosophie des jungen Leibniz in ihrem ideengeschichtlichen Kontext, "Studia Leibnitiana Supplementa", 30.

B. BENNETT, I. DÜNTSCH (2007), Axioms, Algebras and Topology, in Handbook of Spatial Logics, eds. M. Aiello, I. Pratt-Hartmann, J. van Benthem, Dordrecht, Springer.

S. Boethius (1867), De institutione arithmetica, ed. Friedlein, Leipzig, Teubner.

H. Bonitz (1848), Aristotelis metaphysica, Bonn, Marcus.

H. Breger (1986), Leibniz, Weyl und das Kontinuum, "Studia Leibnitiana Supplementa", 26, pp. 316-30.

C. Calosi, P. Graziani, eds. (2014), Mereology and the Sciences. Parts and Wholes in the Contemporary Scientific Context, Heidelberg, Springer.

R. CASATI, A. VARZI (1999), Parts and Places. The Structures of Spatial Representation, Cambridge, MIT Press.

M. CAVEING (1982), Quelques remarques sur le traitement du continu dans les Éléments d'Euclide et la Physique d'Aristote, in Penser les mathématiques, eds. F. Guénard, G. Lelièvre, Paris, Seuil, pp. 145-66.

A.G. COHN, A. VARZI (2003), Mereotopological Connection, "Journal of Philosophical Logic", 32, pp. 357-390.

T. CrocketT (1999), Continuity in Leibniz's mature metaphysics, "Philosophical Studies", 94, pp. 119-38.

R. DedeKIND (1932), Gesammelte Werke, ed. R Fricke, E. Noether, O. Ore, Braunschweig, Bieweg.

V. De RisI, Geometry and Monadology. Leibniz's Analysis Situs and Philosophy of Space, Basel/Boston, Birkhäuser 2007.

V. DE RISI (2015), Leibniz on the Parallel Postulate and the Foundations of Geometry, Basel/Boston, Birkhäuser.

V. DE Risi (2016), The Development of Euclidean Axiomatics. The systems of principles and the foundations of mathematics in editions of the Elements from Antiquity to the Eighteenth Century, in "Archive for History of Exact Sciences", 70, pp. 591-676.

V. DE Risi (2019), Analysis Situs, the Foundations of Mathematics and a Geometry of Space, in The Oxford Handbook of Leibniz, ed. M.R. Antognazza, Oxford, OUP, pp. 247-58.

V. DE RISI (forthcoming A), Gapless Lines and Gapless Proofs. Intersections and Continuity in Euclidean Geometry. 
V. DE RISI (forthcoming B), Has Euclid proven Elements I, 1? The early modern debate on intersections and continuity, in Reading Mathematics in the Early Modern World, ed. P. Beeley, Y. Nasifoglu, B. Wardhaugh, London, Routledge.

J. ECHEVERRÍA (1980), La caractéristique géométrique de Leibniz en 1679, Paris, Sorbonne. (PhD diss.)

J. ECHEVERRÍA (1990), Infini et continu dans les fragments géométriques de Leibniz, in L'infinito in Leibniz, ed. A. Lamarra, Roma, Ateneo, pp. 69-79.

J. Echeverría, M. Parmentier, eds. (1995), G.W. Leibniz, La caractéristique géométrique, Paris, Vrin.

M. Friedman (1992), Kant and the Exact Sciences, Cambridge, Harvard University Press.

L. FroIDMONT (1631), Labyrinthus sive de compositione continui, Antwerp, Moretus.

D. Garber (2015), Leibniz's Transcendental Aesthetic, in Mathematizing Space, ed. V. De Risi, Basel, pp. 231-254.

E. Giovannini (2013), Completitud y continuidad en "Fundamentos de la geometría" de Hilbert: acerca del "Vollständigkeitsaxiom", "Theoria", 28, pp. 139-63.

E. GIUSTI (1990), Immagini del continuo, in L'infinito in Leibniz, ed. A. Lamarra, Roma, Ateneo, pp. 3-32.

T. GLEZER (2017), Kant on reality, Cause, and Force: From the Early Modern Tradition to the Critical Philosophy, Cambridge, CUP.

H. GraßMANN (1847), Geometrische Analyse geknüpft an die von Leibniz erfundene geometrische Charakteristik, Leipzig, Weidmann, now in Gesammelte mathematische und physikalische Werke, I, 1, Leipzig, Teubner 1896-1911.

R. HARTSHORne (2000), Geometry: Euclid and Beyond, New York, Springer.

T.L. HEATH, ed. (1925), Euclid. The Thirteen Books of the Elements, Cambridge, CUP.

G. Hellman, S. Shapiro (2013), The Classical Continuum without Points, "The Review of Symbolic Logic", 6, pp. 488-512.

G. Hellmann, S. Shapiro (2015), Regions-Based Two Dimensional Continua: the Euclidean Case, "Logic and Logical Philosophy", 24, pp. 499-534.

G. Hellman, S. Shapiro (2018), Varieties of Continua. From Regions to points and back, Oxford, OUP.

D. Hilbert (1968), Grundlagen der Geometrie, Leipzig, Teubner (first ed. Leipzig1899).

D. JESSEPH (2015), Leibniz on The Elimination of Infinitesimals, in G. W. Leibniz, Interrelations Between Mathematics and Philosophy, eds. P. Beeley, N. Goethe, D. Rabouin, Springer, Dordrecht, pp. 189-205.

V. Jullien, ed. (1996), Eléments de géométrie de G.P. de Roberval, Paris, Vrin.

G.W. LeIBNIZ (1846), Historia et origo calculi differentialis, ed. C.I. Gerhardt, Hannover, Hahn 1846.

G.W. LeIBNIZ (GM), Mathematische Schriften, ed. C.I. Gerhardt, Berlin/Halle 1849-1863.

G.W. LeIBNIZ (BW), Briefwechsel zwischen Leibniz und Ch. Wolff, edited by C.I. Gerhardt, Halle 1860.

G.W. LeIBNIZ (GP), Die philosophischen Schriften, ed. C.I. Gerhardt, Berlin, Weidmann $1875-1890$.

G.W. LeIBNIZ (C), Opuscules et fragments inédits, ed. L. Couturat, Paris, Alcan 1903.

G.W. LeIBNIZ (A), Sämliche Schriften und Briefe, Darmstadt/Leipzig/Berlin, Akademie 1923-. 
S. LEVEY (1998), Leibniz on Mathematics and the Actually Infinite division of matter, "The Philosophical Review", 107, pp. 49-96.

S. LEVEY (1999), Matter and two concepts of continuity in Leibniz, "Philosophical studies", 94, pp. 81-118.

S. LeVey (2003), The Interval of Motion in Leibniz's Pacidius Philalethi, "Nous", 3, pp. 371416.

D. LEWIS (1991), Parts of Classes, Oxford, Blackwell.

Ø. Linnebo, S. Shapiro, G. Hellman (2015), Aristotelian Continua, "Philosophia Mathematica", 24, pp. 214-46.

M. Mugnai (2000), Two Leibniz Texts with Translations: LH IV 1, 9 r and LH IV 1, Bl. 24 $r$, "The Leibniz Review", 10, p. 135.

C.R. PAlmerino (2015), Libertus Fromondus' Escape from the Labyrinth of the Continuum (1631), "Lias", 42, pp. 3-36.

C.R. Palmerino (2016), Geschichte des Kontinuumproblems or Notes on Fromondus's

Labyrinthus? On the true nature of LH XXXVII, IV, 57r-58v, "The Leibniz Review", 26, pp. 63-98.

M. PAnZa (1992), De la Continuité comme Concept au Continu comme Objet, in Le labyrinthe du continu, eds. J.-M. Salanskis, H. Sinaceur, Berlin, Springer, pp. 16-30.

I. Pratt-Hartmann (2007), First-Order Mereotopology, in Handbook of Spatial Logics, eds. M. Aiello, I. Pratt-Hartmann, J. van Benthem, Dordrecht, Springer, pp. 13-98.

D. Rabouin, ed. (2018), G.W. Leibniz. Mathesis Universalis. Écrits sur la Mathématique Universelle, Paris, Vrin.

A. RoberT (2009), William Crathorn's mereotopological atomism, in Atomism in Late Medieval Philosophy, eds. C. Grellard, A. Robert, Brill, Leyden.

A. RoBINET, ed. (1957), Correspondance Leibniz-Clarke, Paris, PUF.

P. Roeper (2006), The Aristotelian Continuum. A formal characterization, "Notre Dame Journal of Formal Logic”, 47, pp. 211-32.

K. SEREDA (2015), Leibniz's Relational Conception of Number, “The Leibniz Review”, 25, pp. 31-54.

E.D. SYLla (1982), Infinite Indivisibles and Continuity in Fourteenth-Century Theories of Alteration, in Infinity and Continuity in Ancient and Medieval Thought, ed. N.

Kretzmann, Ithaca, Cornell University Press, pp. 231-57.

A. VARZI (1994), On the Boundary Between Mereology and Topology, in Philosophy and the Cognitive Sciences. Proceedings of the 16th International Wittgenstein Symposium, ed. R. Casati, B. Smith, G. White, Vienna, Hölder, pp. 423-442.

G. Vitali (1923), Della continuità nella geometria elementare, in Questioni riguardanti le matematiche elementari, ed. F. Enriques, Bologna, Zanichelli, vol. 1, pp. 193-230.

M.J. White (1988), On Continuity: Aristotle versus Topology?, "History and Philosophy of Logic", 9, pp. 1-12.

M.J. White (1992), The Continuous and the Discrete: Ancient Physical Theories From a Contemporary Perspective, Oxford, OUP.

R.L. Wilder (1978), Evolution of the Topological Concept of "Connected", "The American Mathematical Monthly", 85, pp. 720-26.

J. WyCLIF (1893), Tractatus de logica, ed. M.H. Dziewicki, London, The Wyclif Society. 